\title{
Modeling of photolysis rates over Europe: impact on chemical gaseous species and aerosols
}

\author{
E. Real and K. Sartelet \\ CEREA, Joint laboratory Ecole des Ponts ParisTech/EDF R\&D, Université Paris-Est, 77455 - Champs sur Marne, France
}

Received: 13 April 2010 - Published in Atmos. Chem. Phys. Discuss.: 5 July 2010

Revised: 24 November 2010 - Accepted: 18 January 2011 - Published: 23 February 2011

\begin{abstract}
This paper evaluates the impact of photolysis rate calculation on simulated European air composition and air quality. In particular, the impact of the cloud parametrisation and the impact of aerosols on photolysis rates are analysed. Photolysis rates are simulated using the Fast-JX photolysis scheme and gas and aerosol concentrations over Europe are simulated with the regional chemistry-transport model Polair3D of the Polyphemus platform. The photolysis scheme is first used to update the clear-sky tabulation of photolysis rates used in the previous Polair3D version. Important differences in photolysis rates are simulated, mainly due to updated cross-sections and quantum yields in the Fast-JX scheme. In the previous Polair3D version, clouds were taken into account by multiplying the clear-sky photolysis rates by a correction factor. In the new version, clouds are taken into account more accurately by simulating them directly in the photolysis scheme. Differences in photolysis rates inside clouds can be large but outside clouds, and especially at the ground, differences are small.
\end{abstract}

To take into account the impact of aerosols on photolysis rates, Polair3D and Fast-JX are coupled. Photolysis rates are updated every hour. Large impact on photolysis rates is observed at the ground, decreasing with altitude. The aerosol specie that impact the most photolysis rates is dust especially in south Europe. Strong impact is also observed over anthropogenic emission regions (Paris, The Po and the Ruhr Valley) where mainly nitrate and sulphate reduce the incoming radiation. Differences in photolysis rates lead to changes in gas concentrations, with the largest impact simulated on $\mathrm{OH}$ and $\mathrm{NO}$ concentrations. At the ground, monthly mean concentrations of both species are reduced over Europe by around 10 to $14 \%$ and their tropospheric burden by around $10 \%$. The decrease in $\mathrm{OH}$ leads to an increase of

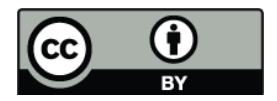

Correspondence to: E. Real

(elsa.real@cerea.enpc.fr) the life-time of several species such as VOC. $\mathrm{NO}_{2}$ concentrations are not strongly impacted and $\mathrm{O}_{3}$ concentrations are mostly reduced at the ground $(-3 \%) . \mathrm{O}_{3}$ peaks are systematically decreased because of the $\mathrm{NO}_{2}$ photolysis rate coefficient decrease. Not only gas are impacted but also secondary aerosols, due to changes in gas precursors concentrations. However changes in aerosol species concentrations often compensate each other resulting in a low impact on $\mathrm{PM}_{10}$ and $\mathrm{PM}_{2.5}$ concentrations (lower than $2 \%$ ).

The changes in gas concentrations at the ground induced by the modification of photolysis rates (by aerosols and clouds) are compared to changes induced by 29 different model parametrisations in Roustan et al. (2010). Among the 31 model parametrisations, "including aerosols on photolysis rates calculation" has the strongest impact on $\mathrm{OH}$ concentrations and on $\mathrm{O}_{3}$ bias in July.

In terms of air quality, ground concentrations $\left(\mathrm{NO}_{2}, \mathrm{O}_{3}\right.$, $\left.\mathrm{PM}_{10}\right)$ are compared with measurements. Changes arising from cloud parametrisation are small. Simulation performances are often slightly better when including aerosol in photolysis rates calculation. The systematic $\mathrm{O}_{3}$ peak reduction leads to large differences in the exceedances of the European $\mathrm{O}_{3}$ standard as calculated by the model, in better agreement with measurements. The number of exceedances of the information and the alert threshold is divided by 2 when the aerosol impact on photochemistry is simulated. This shows the importance of taking into account aerosols impact on photolysis rates in air quality studies.

\section{Introduction}

Photolysis reactions play a major role in the atmospheric composition. In the troposphere, they drive both $\mathrm{O}_{3}$ production through $\mathrm{NO}_{2}$ photolysis $(\lambda<330 \mathrm{~nm})$ :

Published by Copernicus Publications on behalf of the European Geosciences Union. 
$\mathrm{NO}_{2}+h v \stackrel{\mathrm{JNO}_{2}}{\longrightarrow} \mathrm{NO}+\mathrm{O}\left({ }^{3} \mathrm{P}\right)$

$\mathrm{O}\left({ }^{3} \mathrm{P}\right)+\mathrm{O}_{2}+\mathrm{M}->\mathrm{O}_{3}+\mathrm{M}$

and $\mathrm{O}_{3}$ destruction through its own photolysis $(\lambda<420 \mathrm{~nm})$ :

$\mathrm{O}_{3}+h v \stackrel{\mathrm{JO}^{1} \mathrm{D}}{\longrightarrow} \mathrm{O}^{1} \mathrm{D}+\mathrm{O}_{2}$

The latest reaction is also the main source of $\mathrm{OH}$ radicals (in presence of water vapour):

$\mathrm{O}_{2}+\mathrm{H}_{2} \mathrm{O}->2 \mathrm{OH}$

$\mathrm{OH}$ radical is the primary oxidising sink of $\mathrm{CO}$, methane and other hydrocarbons. It also drives the formation of oxidised forms of nitrogen species ( $\mathrm{PAN}$ and $\mathrm{HNO}_{3}$ ) and therefore the availability of $\mathrm{NO}_{2}$ for $\mathrm{O}_{3}$ formation.

Furthermore $\mathrm{OH}$ is involved in the formation of secondary aerosols as the main oxidant of their gas precursors: $\mathrm{SO}_{2}$ for the formation of sulphate, VOC (Volatile Organic Hydrocarbons) for the formation of Secondary Organic Aerosol (SOA) and $\mathrm{NO}_{2}$ for the formation of $\mathrm{HNO}_{3}$ which may condense to form nitrate.

Because of their impacts on both gas and aerosol atmospheric compositions, photolysis rates need to be accurately modeled in global tropospheric studies and regional air quality studies.

The photolysis rate coefficient $J(i)$ for a gaseous species i depend on the wavelength $\lambda$ and can be described as follow:

$J(i)=\int_{\lambda} \sigma_{i}(\lambda, P, T) \Phi_{i}(\lambda, P, T) F(\lambda) d \lambda$

where $\sigma_{i}$ and $\Phi_{i}$ are respectively the absorption cross section and the quantum yield of the $i$ species, and $F$ is the actinic flux representative of the irradiance which reaches the level where $J$ is calculated. $\sigma_{i}$ and $\Phi_{i}$ are specific to the photolysed species $i$ whereas $F$ depends on the position of the sun but also on the presence of clouds and aerosols. To correctly simulate photolysis rates, it is necessary to precisely know absorption cross sections and actinic fluxes. Fluxes are strongly impacted by the presence of aerosols and clouds.

In an aerosol layer, light beams can be either scattered or absorbed depending on aerosol optical characteristics, i.e their Optical Properties (OP) at the beam wavelength, and their Optical Depths (OD) which, given their OP, characterise the aerosol loading. In a cloud layer, light is only scattered. Photolysis rates can be modified by aerosols and clouds inside the layer but also below and above it.

(Dickerson et al., 1997) first showed the importance of the aerosol impact on photolysis rates and on photochemistry for case studies in 1-D (no horizontal dimension). The first analyses of this impact over large regions were conducted from 2003 using global Chemistry Transport Models (CTM) (Liao et al., 2003; Martin et al., 2003; Tie et al., 2005). These global models calculated on-line photolysis rates coefficients, i.e. calculated photolysis rates directly in the CTM.
However this impact is most of the time ignored in air quality studies at the regional scale. To our knowledge, there is only one study performed with a regional model that reports the regional impact of modifications of photolysis rates by aerosols on gas concentrations in Asia (Tang et al., 2003). The large majority of air quality models or regional CTMs do not calculate on-line photolysis rates coefficient and only use a pre-calculated tabulation of clear-sky photolysis rates coefficients. The tabulation depends on latitude, time of the year and SZA. Aerosols are usually taken into account as a spatially and temporally uniform attenuation factor when computing the clear-sky tabulated photolysis rate coefficients. To model the attenuation of solar radiation by clouds, the clearsky tabulated photolysis rate coefficients are usually multiplied by an attenuation coefficient which depends on cloud model data.

Several global model studies analysed the impact on gas concentrations of taking into account the alteration of solar radiation by aerosols (Liao et al., 2003; Martin et al., 2003; Tie et al., 2005). Results were inhomogeneous but all studies simulated a decrease of photolysis rates at the ground. The highest decrease of monthly mean photolysis rates was simulated below dust and forest fire aerosols (up to $-50 \%$ in Martin et al., 2003) which are both absorbing species. Impact on gas concentrations was strong for global $\mathrm{OH}$ tropospheric burden but not really for global $\mathrm{O}_{3}$ burden. However, a strong regional impact was simulated (up to -5 to $-15 \%$ of ground $\mathrm{O}_{3}$ concentrations over biomass burning regions). The impact on aerosol concentrations has not been studied yet.

In this study, the impact of the alteration of photolysis rates by clouds and aerosols is studied at a regional scale over Europe. Not only the modifications of photolysis rates are analysed but also the impact on gas concentrations and on the formation of secondary aerosols. Even though vertical profiles are discussed, emphasis is given on the impact on ground concentrations and regional air quality. The objective of this paper is to estimate how a more realistic simulation of photolysis rates influences air quality and regional air composition and how important it is for air quality simulations. At first, the regional CTM is briefly described, as well as the photolysis schemes used and the on-line treatment of solar-radiation alteration by clouds and aerosols. In the second part, the impact of using two different photolysis schemes on clear-sky photolysis rates is studied. The impact of the parametrisation used for modelling the alteration of solar radiation by clouds and the aerosol impact on solar radiation are then detailed. Finally, these impacts are compared to model uncertainties at ground level and simulation results are compared to ground measurements (including exeedances of air quality standards). 


\section{Model description and setting of the simulation}

\subsection{Model description}

\subsubsection{The Chemistry Transport Model: Polair3D of the Polyphemus platform}

Polyphemus is a platform containing several atmospheric models (Gaussian, Eulerian, Lagrangian). The ChemistryTransport Model (CTM) Polair3D of Polyphemus has been used for many applications: e.g. sensitivity analysis of ozone (Mallet, 2005), of particulate matter (Sartelet et al., 2008; Roustan et al., 2010), modelling of mercury and heavy metal at continental scale (Roustan and Bocquet, 2006) etc... The simulations presented here are carried out at a continental scale, over Europe for 2 months (July and November 2001). The model has been validated for the year 2001 over Europe (Sartelet et al., 2007) with respect to 3 European databases (European Monitoring and Evaluation Programme (EMEP), BDQA and AirBase).

For gaseous chemistry, the chemical mechanism used in the model is the Regional Atmospheric Chemistry Mechanism (RACM) (Stockwell et al., 1997) (82 gas species). Aerosols are simulated using the SIze REsolved Aerosol Model (SIREAM) (Debry et al., 2007). SIREAM includes 16 aerosol species: 3 primary (mineral dust, black carbon and primary organic species), 5 inorganic species (ammonium, sulphate, nitrate, chloride and sodium) and 8 organic species modeled by the Secondary ORGanic Aerosol Model (SORGAM) (Schell et al., 2001). The thermodynamic module used for inorganics is ISORROPIA (Nenes et al., 1999).

Aerosols and gas are scavenged by dry deposition, belowcloud scavenging and in-cloud scavenging. Coagulation and condensation are taken into account and gas and aerosols are assumed to be in thermodynamic equilibrium. Aqueousphase chemistry inside droplets is modeled with the Variable Size Resolved Model (Fahey and Pandis, 2003).

In the standard version of Polyphemus, photolysis rate coefficients are extracted from a clear-sky tabulation. In previous simulations with the model Polair3D, the tabulation was computed with the JPROC photolysis scheme (Roselle et al., 1999). In J-PROC tabulation, aerosols are represented by a constant tropospheric aerosol profile with an optical depth of 0.3 . Modification of photolysis rates by clouds is accounted for by using an attenuation coefficient (see Sect. 2.1.3). In this paper, both cloud and aerosol impacts on photolysis rates are simulated in a more realistic way using the photolysis scheme Fast-J.

A detailed set-up of the version of Polair3D used for this study is described Sect. 2.2.

\subsubsection{The photolysis scheme: Fast-J}

Fast-J is a photolysis scheme (it calculates photolysis rate coefficients) designed to be used on-line in CTMs (Wild and Akimoto, 2001). The specificity of the model is its ability to represent 2-D multiple-scattering of light by aerosols and clouds. In J-PROC, the scattering function is only described by one parameter giving information on scattreing (forward versus backward) (Joseph et al., 1976). Fast-J uses 18 wavelength bins to discretise the solar spectrum. This is much less than other radiative models (usually more than 170 , as in JPROC) in order to save computational time. The UV and low visible part of the spectrum is the most refined part, the effect on $\mathrm{JO}^{1} \mathrm{D}$ and $\mathrm{JNO}_{2}$ is therefore well separated. With these 18 bins, errors relative to the standard photolysis scheme are lower than $3 \%$ (for $\mathrm{NO}_{2}, \mathrm{O}_{3}, \mathrm{H}_{2} \mathrm{O}_{2}$ and $\mathrm{HNO}_{3}$ photolysis rate coefficients).

Aerosols and clouds are represented in the model through their optical depths and optical properties at different wavelengths. Fast-J requires the following OP as input of the model: the single scattering albedo, the extinction coefficient and the phase function (expressed as the 8 first terms of its Legendre expansion). For aerosols, these OP are calculated with a Mie model and depend on the aerosol refractive index and aerosol size. For clouds, pre-calculated values of OP are included in Fast-J for several cloud droplet sizes and ice crystal shapes.

In this paper, the last updated version of Fast-J, namely Fast-JX is used. Photolysis rates calculated by the Fast-JX model have been evaluated at the surface by Barnard et al. (2004) and through the troposphere in the presence of clouds by Voulgarakis et al. (2009).

\subsubsection{On-line treatment of the solar radiation alteration by clouds}

In the standard version of Polyphemus, the impact of clouds on photolysis rates is calculated through an attenuation coefficient $A_{t t}$ applied to clear-sky photolysis rate coefficients (Roselle et al., 1999). This method is adapted from the method of Chang et al. (1987), except for the cloud OD where empirical formula from Stephens (1978) is used. In this method, clouds are represented as a single layer. Then, the attenuation coefficient depends on the Solar Zenith Angle (SZA), the Liquid Water Content (LWC) and whether the level considered is above, in or below the single cloud layer.

This parametrisation can be seen as a first-order approach but there are some conditions under which the approximation is inappropriate, for example in the presence of multiple layers of clouds (only one layer is simulated). In such cases, a full treatment of scattering/absorption of solar radiation in and between vertical clouds is necessary. Here the Fast-JX model is used and clouds are directly taken into account in the computation of photolysis rates. Cloud OD $\tau$ is computed in each layer of the model if a cloud is diagnosed (in 
that way, multiple vertical cloud layers can be simulated). Cloud OD is estimated from LWC and IWC (Ice Water Content) using the formula of Rockel et al. (1991) adapted by Pozzoli et al. (2008):

$\tau=a_{w, \lambda} \times \mathrm{LWP} \times r_{\mathrm{eff}, w}^{b_{w, \lambda}}$

$\tau=a_{i, \lambda} \times \mathrm{IWP} \times r_{\mathrm{eff}, i}^{b_{i, \lambda}}$

where LWP and IWP represent the liquid and ice water paths, i.e. the integration of the LWC and the IWC over the altitude. The parameters $a_{w, \lambda}, b_{w, \lambda}$ (for water) and $a_{i, \lambda}, b_{i, \lambda}$ (for ice) were derived from the Rockel et al. (1991) results. Those results were fitting at the wavelengths used in Fast-JX by Pozzoli et al. (2008) resulting in the following values : $a_{w, \lambda}=1.5$, $b_{w, \lambda}=-0.9, a_{i, \lambda}=1.9$ and $b_{i, \lambda}=-1.1$. The droplet and ice crystal effective radius, $r_{\mathrm{eff}, w}$ and $r_{\mathrm{eff}, i}$, are prescribed (10 $\mu \mathrm{m}$ and $50 \mu \mathrm{m}$ respectively).

Apart from OD, the other parameters required by Fast-JX are the cloud OP. Here, we use the Fast-JX prescribed values (see Sect. 2.1.2) for cloud droplets and irregular-ice crystals. A constant droplet size of $10 \mu \mathrm{m}$ has been chosen following previous studies (Tie et al., 2005; Liu et al., 2006) and for coherence with the cloud OD calculation.

The specification of cloud OD, OP and cloud fraction in each layer is not sufficient to calculate radiative transfer. In general a cloud does not cover the entire horizontal grid box of the model. Knowledge of how multiple cloud layers overlap, i.e. knowledge of the cloud vertical coherence, is therefore required to calculate cloud OD. Here the scheme developed by Briegleb (1992) is used. In this scheme, the cloud OD in each layer is weighted by the cloud cover fraction raised to the power of $3 / 2$. It is a good approximation of more complex but time-consuming shemes and is used in several CTM studies (Feng et al., 2004; Pozzoli et al., 2008).

\subsubsection{On-line treatment of the solar radiation alteration by aerosols}

In the presence of clouds, photolysis rates can be computed in a preprocessing stage (i.e. before running the CTM) as only meteorological data (relative humidity, LWC and IWC data) are required to run the photolysis scheme. In contrast, photolysis rate calculation in the presence of aerosols must be done on-line in the CTM, as aerosol concentrations are calculated at each model time-step.

In the on-line treatment of the aerosol impact on solar radiation, OD and OP are calculated at each grid box of the CTM from the simulated aerosol 3-D concentrations. The OD and OP 3-D distributions are then used as input of the photolysis scheme Fast-JX which calculates the photolysis rate 3D distribution. Newly calculated photolysis rates are used for the following time step of the CTM to calculate gas and aerosols concentrations. Thereby, the simulated aerosol concentrations influence photolysis rates, which directly influence gas-phase concentrations. The impact on gas-phase concentrations also induces an impact on aerosol concentrations.

To translate aerosol concentrations in OD and OP the method used by Tombette et al. (2008) is used: given the particle refractive index and its wet diameter, a tabulation based on a Mie code provide the OP. The Mie model developed by Mishchenko et al. (1999) is used here because it calculates the 8 first terms of the Legendre expansion of the phase function (see Sect. 2.1.2) required by Fast-J.

The refractive index of a particle composed of several species is estimated from the individual refractive indexes of each aerosol species and the particle mixing state. Although the CTM assumes particles to be internally mixed, different mixing state may be used when computing the refractive index (Tombette et al., 2008). Here, aerosol species are assumed to be well mixed except black carbon which constitutes a core. Refractive indexes of all individual aerosol species are taken from the OPAC (Optical Properties of Aerosols and Clouds, Hess et al., 1998) software package. The wet diameter is calculated using the aerosol liquid water content calculated in the CTM with Isorropia.

In this study, photolysis rate coefficients are updated (recalculated with Fast-JX from aerosol concentrations) every hour. For the simulation described below, the computing time increases only by $2.5 \%$ when updating photolysis rates coefficients hourly. Simulations with photolysis rate coefficients updated hourly and every $10 \mathrm{~min}$ have been compared and only very small differences in the gas and aerosol concentrations $(<1 \%)$ were found.

\subsection{Model set-up}

The model is run for the months of July and November 2001 over Europe. Model set-up is the same as in Sartelet et al. (2007) except for the vertical resolution. The main characteristics of the configuration are summarized below.

The horizontal step is $0.5^{\circ} \times 0.5^{\circ}$ and 13 vertical levels from 0 to $10 \mathrm{~km}$ are used. Meteorological fields are provided by the European Centre for Medium-range Weather Forecast with an horizontal step of $0.36^{\circ} \times 0.36^{\circ}$ and a $3 \mathrm{~h}$ time-step. The boundary conditions for gas are taken from the MOZART 2 model (Horowitz et al., 2003) and from the GOCART model (Chin et al., 2000) for aerosol concentrations. In previous studies, GOCART dust boundary conditions were reduced by 4 (Vautard et al., 2005; Sartelet et al., 2007). To validate this drastic division, the GOCART simulated total optical depth is compared to measurements from the AERONET (AErosol RObotic NETwork) database for the entire year 2001 over Europe. The GOCART simulated ODs agree better with measurements when dust concentrations are divided by 4 . Accordingly, we divided the GOCART dust concentrations by 4 in our model. GOCART AOD with and without dividing dust concentrations by 4 are similar to those simulated with our model for the months of July and November (see Table 2). 
Table 1. Model schemes, characteristics and parameters.

\begin{tabular}{|c|c|c|c|c|c|c|c|c|}
\hline & $\begin{array}{l}\text { Scattering } \\
\text { treatment }\end{array}$ & $\begin{array}{l}\text { Number of } \\
\text { wavelength } \\
\text { bins }\end{array}$ & $\begin{array}{l}\mathrm{O}_{3} \\
\text { vertical } \\
\text { profile }\end{array}$ & $\begin{array}{l}\text { Temperature } \\
\text { profile }\end{array}$ & $\begin{array}{l}\text { aerosol } \\
\text { profile }\end{array}$ & $\begin{array}{l}\mathrm{O} 2 \\
\text { profile }\end{array}$ & $\begin{array}{l}\text { Earth } \\
\text { albedo }\end{array}$ & $\begin{array}{l}\text { Cross } \\
\text { section }\end{array}$ \\
\hline J-PROC & 2-stream & 170 & DeMore et al. (1994) & Chang et al. (1987) & $\begin{array}{l}\text { Elterman }(1968) \\
\text { OD at } 340 \mathrm{~nm}: \\
0.379\end{array}$ & DeMore et al. (1994) & Demerjian et al. (1980) & $\begin{array}{l}\text { Gery et al. (1989) } \\
\text { and } \\
\text { JPL } 94 \\
\text { (DeMore et al., 1994) }\end{array}$ \\
\hline FAST-JX & $\begin{array}{l}\text { multiple } \\
\text { scattering } \\
(8 \text { stream })\end{array}$ & 18 & Labow et al. (2004) & Wang et al. (1992) & NONE & IDEM & 0.1 & $\begin{array}{l}\text { Mainly JPL } 02 \\
\text { (Sander et al., 2002) }\end{array}$ \\
\hline
\end{tabular}

\section{Results and discussion}

As explained in Sect. 1, the photolysis rate of $\mathrm{NO}_{2}$ (characterised by its coefficient $\mathrm{JNO}_{2}$ ) and the photolysis rate of $\mathrm{O}_{3}$ (characterised by its coefficient $\mathrm{JO}^{1} \mathrm{D}$ ), are very important to understand tropospheric chemistry as they influence respectively $\mathrm{O}_{3}$ production and $\mathrm{O}_{3}$ destruction, as well as $\mathrm{OH}$ production. In the following section, when analysing impact on photolysis rates, we mainly focus on these 2 photolysis rates, even though others photolysis rates are mentioned.

Differences between simulations are mainly expressed in terms of relative differences. When not specified these relative differences are calculated at each grid point of the model (local relative differences) and each time-step. Then they are averaged over the simulated month.

\subsection{Impact of changing the photolysis scheme}

In this section, we briefly study the sensitivity of photolysis rates and concentrations on the photolysis scheme. Two photolysis schemes used to compute clear-sky tabulation of photolysis rate coefficients are compared. This is interesting in order to understand what parameters, data or physical hypothesis influence the most the photolysis rate calculation and what changes are expected when changing or updating the photolysis scheme used in a CTM.

The main differences between the two photolysis schemes in their default configuration (JPROC and FAST-JX) are summarised in Table 1. The two models used different physical treatments of scattering, numbers of wavelength bins, $\mathrm{O}_{3}$ profiles, temperature, $\mathrm{O}_{2}$ and aerosol profiles as well as different earth albedo, cross-sections and quantum yields. In JPROC, cross sections and quantum yields from RADM dated from 1988 are used whereas updated JPL 2002 crosssections (Sander et al., 2002) are used in Fast-JX. With these configurations, important differences are found between photolysis rates simulated with these two different schemes. For the photolysis rate coefficients of $\mathrm{NO}_{2}$ and $\mathrm{O}_{3}$, mean relative differences of $21 \%$ and $32 \%$ are simulated. Differences can be much larger for some photolysis rate coefficients, for example $\mathrm{HNO}_{3}(63 \%)$ or $\mathrm{HNO}_{4}(219 \%)$.

Different tests have been conducted to understand which parameters drive the differences in photolysis rates between the 2 models. We found that when using the same aerosol profiles, the same earth albedo and the same cross-sections and quantum yields for both models, differences in photolysis rates are reduced to values between 1 and $12 \%$ (for all photolysis rates). Among the 3 parameters identified as the most influencing the photolysis rates, differences in crosssections and quantum yields dominate (on average, about $70 \%$ of the photolysis differences are due to those differences). Aerosol profiles and earth albedo both account for around $10 \%$. The remaining differences probably come from the intrinsic use of 18 wavelengths in Fast-JX instead of 171 in JPROC, differences should be lower than $3 \%$ according to Wild and Akimoto (2001) and from the intrinsic difference in scattering treatments in the two models (2 streams against 8 streams).

CTM simulated concentrations with the two photolysis schemes also show important differences. We will not detail the results in this paper but mean tropospheric $\mathrm{OH}, \mathrm{O}_{3}$ and NO differences of $26,1,20 \%$ and 14,3 and $16 \%$ respectively in winter and summer are found.

To summarize, large differences on photolysis rates are found when using the 2 different photolysis schemes (FastJX and JPROC) to compute clear-sky photolysis rates, leading to large differences in gas concentrations calculated by the CTM. These differences are mainly due (around 70\%) to differences in cross-sections and quantum yields data. Intrinsic differences between the models (i.e wavelength bins and scattering treatments) do not account for more than $12 \%$ of the differences. Cross-sections and quantum yields data used in our version of JPROC were not up-to-date explaining the large differences simulated on photolysis rates. For updated data (JPL), error on photolysis rates are estimated to be at maximum 10\% (Sander et al., 2006). This comparison underlines the importance of using updated cross-sections and quantum yields when computing photolysis rates.

\subsection{Impact of the parametrisation used for modelling alteration of solar radiation by clouds}

In this section we compare photolysis rates and gas concentrations calculated with the "attenuation" method (clear-sky tabulated photolysis rate coefficients calculated with FastJX multiplied by an attenuation factor, R-ATT), to those 
Table 2. Statistics obtained when comparing model OD to AERONET data. The dust boundary conditions of the model either correspond to GOCART dust concentrations (standard) or to GICART dust concentrations divided by 4 (Dust/4). Mean values and RMSE are reported in $\mu \mathrm{g} \mathrm{m}^{-3}$, and RMSE, NMB and NME in \%. Comparison is done at 12 AERONET stations.

\begin{tabular}{|c|c|c|c|c|c|c|c|c|c|c|}
\hline & \multicolumn{5}{|c|}{ Summer } & \multicolumn{5}{|c|}{ Winter } \\
\hline & mean & $r$ & RMSE & NMB & NME & mean & $r$ & RMSE & NMB & NME \\
\hline Measurements & 0.2 & & & & & 0.2 & & & & \\
\hline Standard & 0.6 & $73.9 \%$ & 0.5 & $128 \%$ & $137 \%$ & 0.3 & $47.7 \%$ & 0.3 & $117 \%$ & $122 \%$ \\
\hline Dust/4 & 0.3 & $78.1 \%$ & 0.2 & $20 \%$ & $43 \%$ & 0.2 & $57.4 \%$ & 0.1 & $44 \%$ & $57 \%$ \\
\hline
\end{tabular}

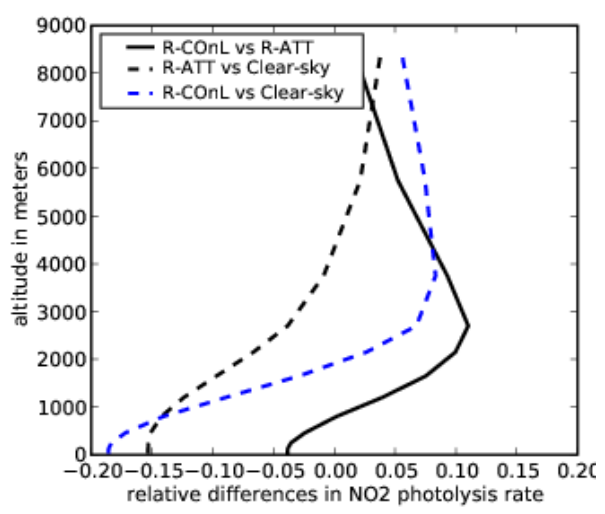

(a) $\mathrm{JNO}_{2}$

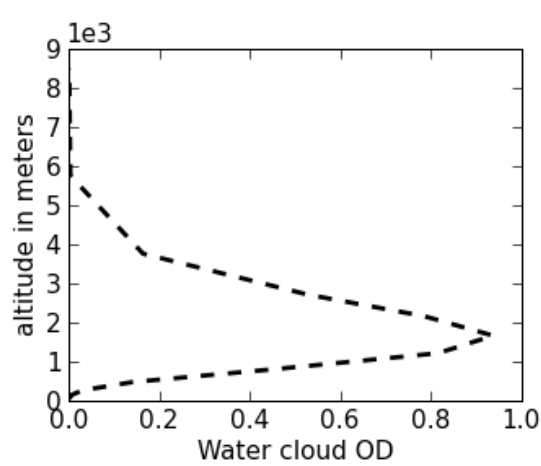

(b) Cloud OD

Fig. 1. Monthly mean vertical profiles of relative differences between NO2 photolysis rates simulated with R-ATT, R-COnL and R-AERO for November 2001. Simulated cloud OD is also shown.

calculated with the full scattering treatment of Fast-JX in presence of clouds, namely the "cloud on-line" method (R$\mathrm{COnL}$ ). These simulations are also compared to a simulation under clear-sky conditions. Photolysis rates are calculated for the months of November and July 2001. Because impacts are larger in November, due to higher cloudiness, only November results are analysed here, but both months are kept for comparison to measurements.

Monthly mean relative differences between the three simulations are shown in Fig. 1 for $\mathrm{NO}_{2}$ photolysis rate coefficient as a function of altitude. Simulated cloud OD is also shown in Fig. 1 to locate altitudes where clouds are. $\mathrm{O}_{3}$ photolysis rate coefficient is not shown but its variation is similar on averaged to the $\mathrm{NO}_{2}$ one. As shown in several previous studies, whatever the parametrisation used, the impact of including clouds in photolysis rate calculation is high over the whole troposphere (from $-18 \%$ at the ground to $+6 \%$ in the free troposphere). Changes arising from choosing one parametrisation or another are lower. At the ground these changes are small, around $-4 \%$ with R-COnL compared to R-ATT. The largest differences are obtain inside clouds where they reach $11 \%$. At the ground, differences are most often smaller than $2 \%$ (during $80 \%$ of the time) but they can sometimes be larger than $50 \%$ ( $3 \%$ of the time). Generally the largest differences are correlated to high total vertical cloud OD. Wild and Akimoto (2001) showed that the benefit from the full scattering treatment of Fast-J is clear for deep cloud (large $\mathrm{OD})$, for which attenuation is strongly non-linear and therefore badly represented by the attenuation coefficient method (R-ATT or Chang et al., 1987 in Wild et al., 2000).

Changes in photolysis rates induce changes in chemical specie concentrations. Monthly mean vertical profiles of relative differences between specie concentrations simulated with R-COnL and R-ATT are shown in Fig. 2 for $\mathrm{O}_{3}, \mathrm{OH}$, $\mathrm{NO}$ and $\mathrm{NO}_{2}$. Overall changes in gas concentrations follow changes in photolysis rates: low at the ground and higher inside and above clouds. OH concentrations respond directly to changes in $\mathrm{O}_{3}$ loss $\left(\mathrm{O}_{3}+\mathrm{h} v \rightarrow \mathrm{O}^{1} \mathrm{D}+\mathrm{O}_{2}\right.$ leads to $\mathrm{OH}$ formation in the presence of water vapour). In general $\mathrm{OH}$ concentrations vary linearly with $\mathrm{JO}^{1} \mathrm{D}$. This was also observed by Lefer et al. (2003) who found a strong linear relationship between $\mathrm{OH}$ and $\mathrm{JO}^{1} \mathrm{D}$ both in the measurement and in their model. This can be explained by a strong dependance of $\mathrm{OH}$ source on photolysis rates whereas $\mathrm{OH}$ sinks are less dependant on those rates. For example, the sink reaction of $\mathrm{OH}$ with $\mathrm{NO}_{2}$ to form $\mathrm{HNO}_{3}$ is influenced by photolysis rate modifications but changes in $\mathrm{NO}_{2}$ concentrations are low in average.

An increase in the $\mathrm{NO}_{2}$ photolysis rate coefficient generally leads to a decrease in $\mathrm{NO}_{2}$ concentrations and an increase in $\mathrm{NO}$ concentrations. The behaviour of $\mathrm{O}_{3}$ is more complex. An increase in $\mathrm{NO}_{2}$ photolysis rate leads 


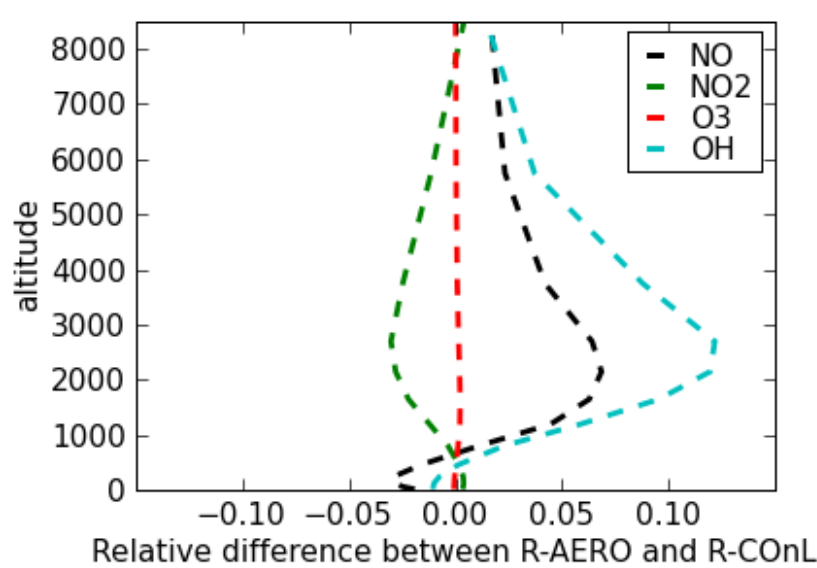

Fig. 2. Relative differences between $\mathrm{O}_{3}, \mathrm{NO}, \mathrm{NO}_{2}$ and $\mathrm{OH}$ concentrations simulated using the "Attenuation" and the "on-line" cloud parametrisations. Values are averaged over Europe and over November 2001.

to an increase in $\mathrm{O}_{3}$ production whereas an increase in $\mathrm{O}_{3}$ photolysis rate destroys $\mathrm{O}_{3}$. An increase in photolysis rates can therefore lead to $\mathrm{O}_{3}$ net production or destruction. If air masses are in a net $\mathrm{O}_{3}$ production regime $\left(\mathrm{O}_{3}\right.$ production $>\mathrm{O}_{3}$ destruction), a similar increase (respectively decrease) in $\mathrm{O}_{3}$ and $\mathrm{NO}_{2}$ photolysis rate coefficients will quantitatively increase (respectively decrease) more $\mathrm{O}_{3}$ production than destruction, leading to an increase (respectively decrease) in $\mathrm{O}_{3}$ net production. Similarly, if air masses are in a net destruction regime, an increase (decrease) in photolysis rates will lead to a decrease (increase) in $\mathrm{O}_{3}$ concentrations. Because of this duality, differences will only be large where one of the two terms $\left(\mathrm{O}_{3}\right.$ production or destruction) strongly dominates the other. This explains why changes in $\mathrm{O}_{3}$ are mainly simulated at the ground, where net $\mathrm{O}_{3}$ production or destruction can be large, and not in the mean free troposphere where production usually compensates destruction. At the ground, the $\mathrm{O}_{3}$ production regime dominates and therefore a decrease in photolysis rates leads to a decrease in $\mathrm{O}_{3}$ concentration. $\mathrm{NO}$ and $\mathrm{OH}$ are the most sensitive species to changes in photolysis rates because they are both short-lived species and are produced by photolysis reactions.

The relative differences in tropospheric burden is calculated in Table 3. In contrast to other "locale" relative differences calculated in this paper, these differences are not calculated locally but concentrations are first averaged over the domain (horizontal, temporal and vertical) for each of the 2 runs and then the difference is computed. This mean that important local changes on low concentrations do not strongly impact the tropospheric burden relative differences. The burden differences exceed $2 \%$ only for $\mathrm{NO}$ and $\mathrm{OH}(5 \%$ for $\mathrm{OH}$ ).
In term of air quality implications, it is clear that errors in pollutant concentrations due to the use of the simpler cloud parametrisation (R-ATT) are low at the ground. A better representation of clouds by assimilation of cloud data from satellite for example will have a higher impact on surface $\mathrm{O}_{3}$ (Pour-Biazar et al., 2007).

\subsection{Aerosol impact on solar radiation}

In this section the influence of aerosols on photochemistry through the alteration of photolysis rates is evaluated. To do so, the simulation R-COnL where only clouds are taken into account in the photolysis scheme, is compared to the simulation R-AERO where both clouds and aerosol concentrations impact photolysis rates. Simulations are conducted for July and November 2001 but only July results are detailed.

\subsubsection{Impact on photolysis rates}

We first briefly describe the simulated tropospheric Aerosol OD (AOD). Monthly mean spatial values of the AOD for the month of July are shown over Europe in Fig. 4 together with vertical AOD profiles. Contributions to AOD from each aerosol type are also shown in the vertical AOD profiles. The largest tropospheric AOD values are simulated over south Europe, due to dust aerosols coming from Africa, despite the reduction by a factor 4 of dust boundary conditions (see Sect. 2.2). Regions with strong anthropogenic emissions, such as Paris, the Po valley and the Ruhr valley also clearly contribute to the tropospheric AOD. In such regions, the component that contributes the most to the AOD is nitrate. Eastern Europe also contributes to AOD mainly through sulphate (presence of power plant releasing large $\mathrm{SO}_{2}$ concentrations) and to a lesser extent organic aerosols and black carbon. Overall, the component which impacts the most the AOD is dust followed by sulphate and nitrate. Dust is mainly present above the boundary layer (peaks around $4 \mathrm{~km}$ ) whereas other components exhibit peaks in the boundary layer (around $500 \mathrm{~m}$ ). It should be noticed that forest fires are not included in the emissions. Black carbon concentrations may strongly influence AOD in case of biomass burning. Also, SOA concentrations are underestimated with the SOA model SORGAM (Kim et al., 2011) and the global impact of SOA is probably underestimated.

Mean vertical profiles (averaged over the spatial domain and over the month) of relative differences between $\mathrm{NO}_{2}$ and $\mathrm{O}_{3}$ photolysis rate coefficients simulated with $\mathrm{R}-\mathrm{AERO}$ and R-COnL in July 2001 are shown in Fig. 1. Relative differences between R-COnL and R-ATT are also shown in order to compare the effects on photolysis rates of changing the cloud parametrisation versus including aerosols.

Including the aerosol impact on solar radiation leads to a mean decrease of all photolysis rates (here only $\mathrm{NO}_{2}$ and $\mathrm{JO}^{1} \mathrm{D}$ are shown but other photolysis rates exhibit the same feature) from the ground to $10 \mathrm{~km}$. This decrease is the 
Table 3. Monthly relative differences between R-AERO and R-COnL in tropospheric burden for July and November.

\begin{tabular}{lrrrrrrrrrrrr}
\hline species & $\mathrm{O}_{3}$ & $\mathrm{NO}_{2}$ & $\mathrm{NO}$ & $\mathrm{OH}$ & $\mathrm{ISO}$ & $\mathrm{HC}_{8}$ & $\mathrm{PM}_{10}$ & $\mathrm{PM}_{2.5}$ & $\mathrm{PNO}_{3}$ & $\mathrm{PSO}_{4}$ & $\mathrm{PNH}_{4}$ & $\mathrm{SOA}$ \\
\hline summer - tropospheric & $-2 \%$ & $+2 \%$ & $-10 \%$ & $-10 \%$ & $+11 \%$ & $+6 \%$ & $-0.1 \%$ & $-0.5 \%$ & $+0.7 \%$ & $-2 \%$ & $+1 \%$ & $-1 \%$ \\
summer - ground & $-3 \%$ & $+2 \%$ & $-13 \%$ & $-14 \%$ & $+8 \%$ & $+5 \%$ & $-0.2 \%$ & $-0.7 \%$ & $+0.7 \%$ & $-3 \%$ & $-1 \%$ & $-2 \%$ \\
winter - tropospheric & $-0.8 \%$ & $-0.2 \%$ & $-14 \%$ & $-10 \%$ & $+9 \%$ & $+2 \%$ & $+2 \%$ & $+2 \%$ & $+4 \%$ & $+1 \%$ & $+3 \%$ & $-1.4 \%$ \\
winter - ground & $-2.5 \%$ & $-0.6 \%$ & $-13 \%$ & $-13 \%$ & $+8 \%$ & $+2 \%$ & $+2 \%$ & $+2 \%$ & $+3 \%$ & $+0.3 \%$ & $+3 \%$ & $-2 \%$ \\
\hline
\end{tabular}

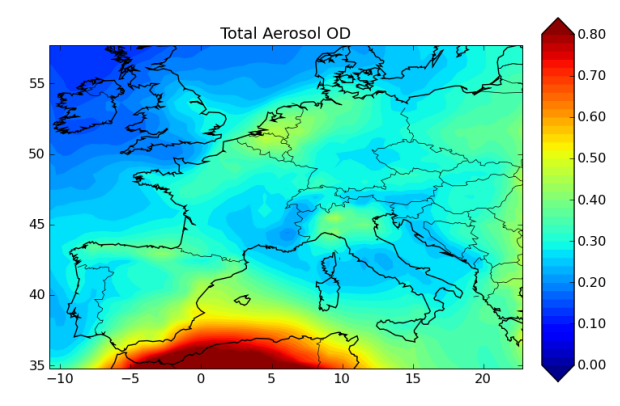

(a) Map

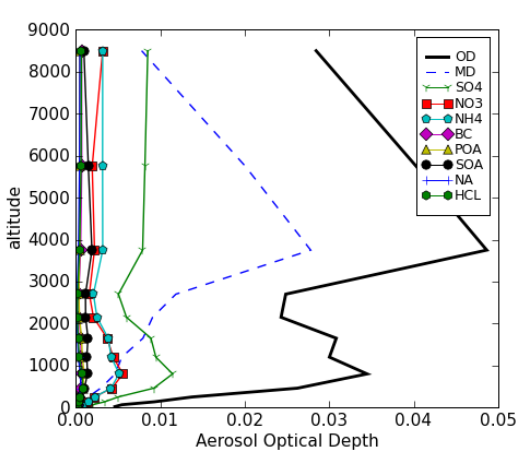

(b) Vertical profile

Fig. 3. (a) Monthly mean tropospheric AOD and (b) vertical profile for July 2001. The contributions of individual aerosol species to OD are also shown in the vertical profile.

highest at the ground $(-13$ to $-14 \%)$ and decreases with altitude. At the ground, the impact is much higher than the impact simulated when changing the cloud parametrisation. He and Carmichael (1999) studied the effect on photolysis rates of an aerosol layer located in the boundary layer depending on aerosol types. They showed that for absorbing aerosols (suwh as urban but also dust aerosols), photolysis rates are reduced through all the tropospheric column whereas for purely scattering aerosols the effect is mainly an increase of photolysis rates above the layer. In our case, the mean AOD is dominated by dust aerosols over the troposphere which are partly absorbing. This explains that the mean photolysis rates at all vertical levels are reduced. The impact of aerosols on photolysis rates is spatially heterogeneous. Figure 5 shows the monthly mean relative differences of $\mathrm{JNO}_{2}$ at the ground in July. It can be seen that a strong decrease of $\mathrm{JNO}_{2}$ for the R-AERO run is correlated with a high tropospheric AOD (highest AOD are simulated in south Europe, Paris and the Ruhr and Po valleys). $\mathrm{JO}^{1} \mathrm{D}$ exhibits the same feature (not shown) with a decrease of the same order of magnitude. At higher vertical levels (starting from around $500 \mathrm{~m}$ height), some regions with high concentrations of scattering aerosols (sulphate for example) in the lower vertical layers show positive differences (largest photolysis rates when including aerosols) above these layers. This is the case for example over Paris, the Po Valley and the Ruhr valley (not shown).
In winter, photolysis rates exhibit the same features but decreases are higher (not shown). This is due to larger SZA in winter than in summer. Yet, the impact of an aerosol layer on solar radiation depends on the SZA. For large SZA, the incidence angle over the aerosol layer is large and so is the time spent by solar beams on it (the optical path). The more time the beams spend on the aerosol layer, the more chance they have to be scattered or absorbed by aerosols and therefore, the more photolysis rates are impacted.

\subsubsection{Impact on 3-D concentrations}

The vertical profiles of relative differences between $\mathrm{R}-\mathrm{AERO}$ and $\mathrm{R}-\mathrm{COnL}$ averaged over the spatial domain for $\mathrm{O}_{3}, \mathrm{NO}_{2}$, $\mathrm{NO}$ and OH concentrations are shown in Fig. 6 for July 2001. The largest differences are observed in $\mathrm{OH}$ and NO concentrations which are reduced all through the troposphere between 2 and 17\% depending on altitude. $\mathrm{NO}$ and $\mathrm{OH}$ are both directly produced by photolysis and they both have a short life-time. The changes in $\mathrm{OH}$ and NO concentrations are almost equivalent to changes in respectively $\mathrm{JO}^{1} \mathrm{D}$ and $\mathrm{JNO}_{2}$ photolysis rate coefficients.

Differences in $\mathrm{O}_{3}$ concentrations are mainly observed close to the ground. As explained Sect. 3.2, differences in $\mathrm{O}_{3}$ concentrations are mostly observed where one of the two terms, $\mathrm{O}_{3}$ production or destruction, dominates, i.e. in the boundary layer. This is detailed in next section. $\mathrm{NO}_{2}$ behaviour is more complex. At the ground, $\mathrm{NO}_{2}$ concentrations 
Table 4. Statistics obtained when comparing monthly hourly $\mathrm{O}_{3}$, peak $\mathrm{O}_{3}$, daily $\mathrm{NO}_{2}$ and daily $\mathrm{PM}_{10}$, measured (meas) and simulated at EMEP stations with R-ATT, R-COnL and R-AERO in July and November. Mean values and RMSE are reported in $\mu \mathrm{g} \mathrm{m}^{-3}$, and RMSE, $\mathrm{NMB}$ and NME in \%. Comparison is done at 92 stations for $\mathrm{O}_{3}, 33$ for $\mathrm{NO}_{2}$ and 26 for $\mathrm{PM}_{10}$.

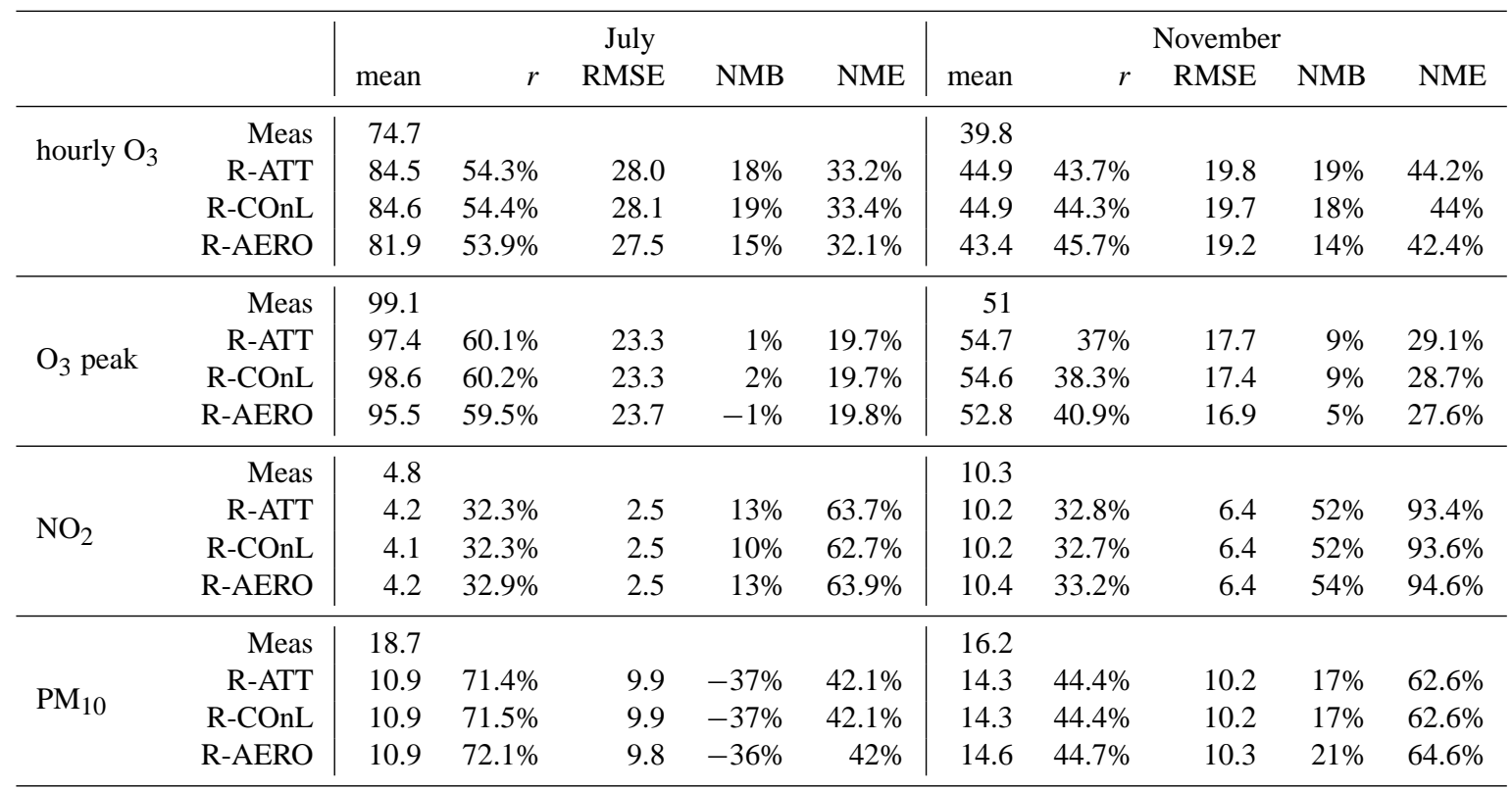

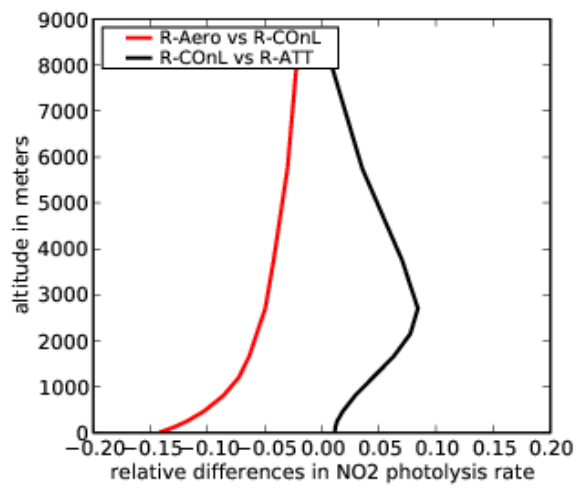

(a) $\mathrm{NO} 2$

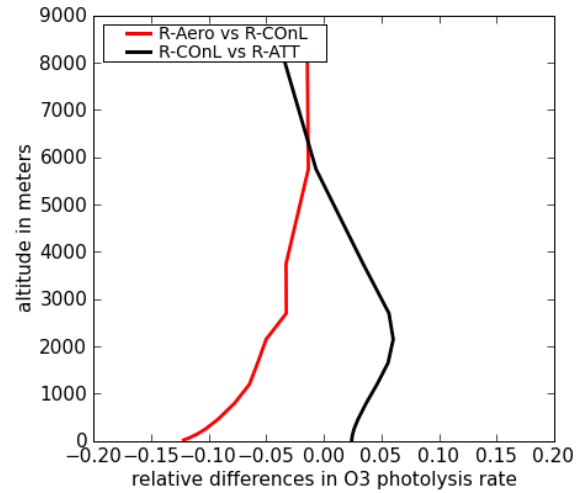

(b) $\mathrm{O} 3$

Fig. 4. Monthly mean vertical profile of relative differences between $\mathrm{NO}_{2}$ and $\mathrm{O}_{3}$ photolysis rates simulated with R-ATT, R-COnL and R-AERO for July 2001.

are higher with R-AERO than with R-COnL but the opposite is simulated between 3 and $4 \mathrm{~km}$ height. To understand the variations of $\mathrm{NO}_{2}$ concentrations, the daily variations of $\mathrm{JNO}_{2}$, and $\mathrm{NO}_{2}$ (averaged over the month of July) are plotted at the ground and at $3 \mathrm{~km}$ in Fig. 7). It can be seen that $\mathrm{JNO}_{2}$ is reduced all through the day at the ground with RAERO but with a larger decrease at the sun-set and sunrise due to larger SZA (and therefore larger optical path). At $3 \mathrm{~km}$ those decreases are limited by the presence of aerosol layers underneaths which scatter light. At noon, this even leads to larger photolysis rates with R-AERO than with R-COnL. At sunrise and sun-set photolysis rates decrease with R-AERO but the decrease is smaller than at the ground. Furthermore, as photolysis rate coefficients of $\mathrm{NO}_{3}$ and $\mathrm{N}_{2} \mathrm{O}_{5}$ are lower, the night time loss of $\mathrm{NO}_{2}$ in favour of $\mathrm{NO}_{3}$ and $\mathrm{N}_{2} \mathrm{O}_{5}$ starts earlier in the evening and the release of $\mathrm{NO}_{2}$ is delayed with $\mathrm{R}$-AERO compared to R-COnL. This leads to a decrease in $\mathrm{NO}_{2}$ concentrations at noon with R-AERO and to smaller increase at early morning and late afternoon, resulting in a daily reduction in $\mathrm{NO}_{2}$ concentrations.

In term of tropospheric burden (see Table 3), $\mathrm{NO}$ and $\mathrm{OH}$ burdens both decrease by $10 \%$ in July and by respectively 10 and $14 \%$ in November with R-AERO. The $\mathrm{NO}_{2}$ tropospheric burden slightly increases in July $(+2 \%)$ and decreases 
Table 5. Statistics obtained when comparing monthly hourly and peak $\mathrm{O}_{3}$ measured and simulated at AIRBASE stations with R-COnL and R-AERO in July and November. Mean values and RMSE are reported in $\mu \mathrm{g} \mathrm{m}^{-3}$, and RMSE, NMB and NME in \%. Comparison is done at 734 stations.

\begin{tabular}{ll|rrrrr|rrrrr}
\hline & & \multicolumn{5}{|c|}{ July } & \multicolumn{5}{c}{ November } \\
& & mean & $r$ & RMSE & NMB & NME & mean & $r$ & RMSE & NMB & NME \\
\hline \multirow{2}{*}{ hourly O3 3} & Meas & 66.3 & & & & & 25.7 & & & & \\
& R-COnL & 87.4 & $56 \%$ & 36.4 & $38 \%$ & $49.3 \%$ & 41.7 & $46.7 \%$ & 25.2 & $97 \%$ & $113 \%$ \\
& R-AERO & 84.1 & $56.6 \%$ & 34.5 & $33 \%$ & $46.5 \%$ & 40.4 & $48.4 \%$ & 24.4 & $90 \%$ & $107 \%$ \\
\hline \multirow{3}{*}{$\mathrm{O}_{3}$ peak } & Meas & 101.3 & & & & & 51 & & & & \\
& R-COnL & 102.9 & $62.2 \%$ & 28.1 & $+4 \%$ & $23.4 \%$ & 52.2 & $41.2 \%$ & 22.7 & $53 \%$ & $63.4 \%$ \\
& R-AERO & 100.2 & $63.8 \%$ & 27.7 & $-2 \%$ & $23.2 \%$ & 50.8 & $44.1 \%$ & 21.7 & $48 \%$ & $59.8 \%$ \\
\hline
\end{tabular}

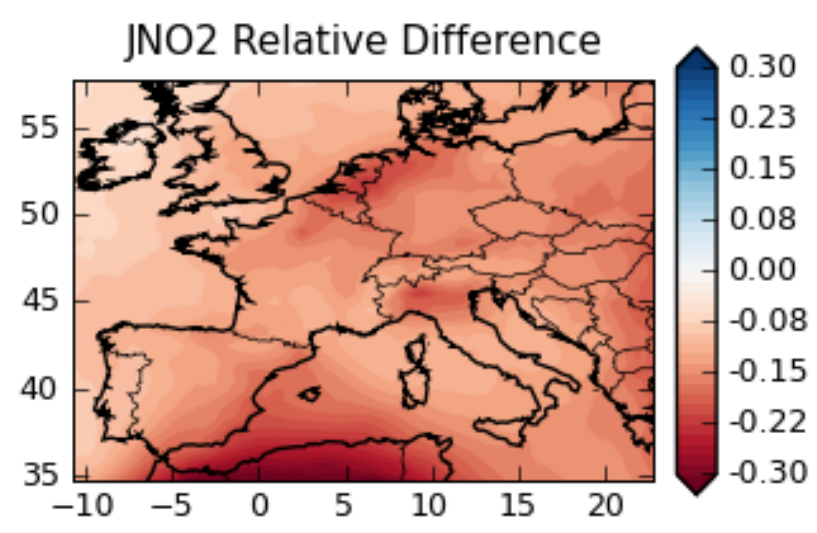

Fig. 5. Ground monthly mean relative difference in $\mathrm{JNO}_{2}$ between R-AERO and R-COnL for July 2001.

in November $(-0.2 \%)$. The $\mathrm{O}_{3}$ tropospheric burden decrease is small, by around 2 and $1 \%$ in July and November respectively, i.e. by around $2 \mu \mathrm{g} \mathrm{m}^{-3}$.

The decrease in $\mathrm{OH}$ concentrations is also observed more generally in $\mathrm{HO}_{\mathrm{x}}$ concentrations $\left(\mathrm{HO}+\mathrm{HO}_{2}\right)$ with $\mathrm{R}$-AERO. Thus the oxidising capacity of the troposphere over Europe is globally reduced. This leads to a reduction of oxidation of several species and to an increase of their lifetime. This is the case for several VOCs as its is shown in the next section.

\subsubsection{Impact on ground concentrations}

In this section, the impact of solar radiation attenuation by aerosols on ground concentrations of gas but also aerosols is studied in details, and in particular the spatial heterogeneity of relative differences. Monthly maps are shown for July only.

Maps of ground relative differences between R-AERO and R-COnL for $\mathrm{OH}, \mathrm{O}_{3}, \mathrm{NO}_{2}$ and $\mathrm{NO}$ are shown in Fig. 9. The map of $\mathrm{OH}$ relative differences is almost identical to the $\mathrm{JNO}_{2}$ one (in fact it is linked to $\mathrm{JO}^{1} \mathrm{D}$, which varies similarly to $\mathrm{JNO}_{2}$ ). The $\mathrm{NO}$ map is also similar to the $\mathrm{JNO}_{2}$ one with

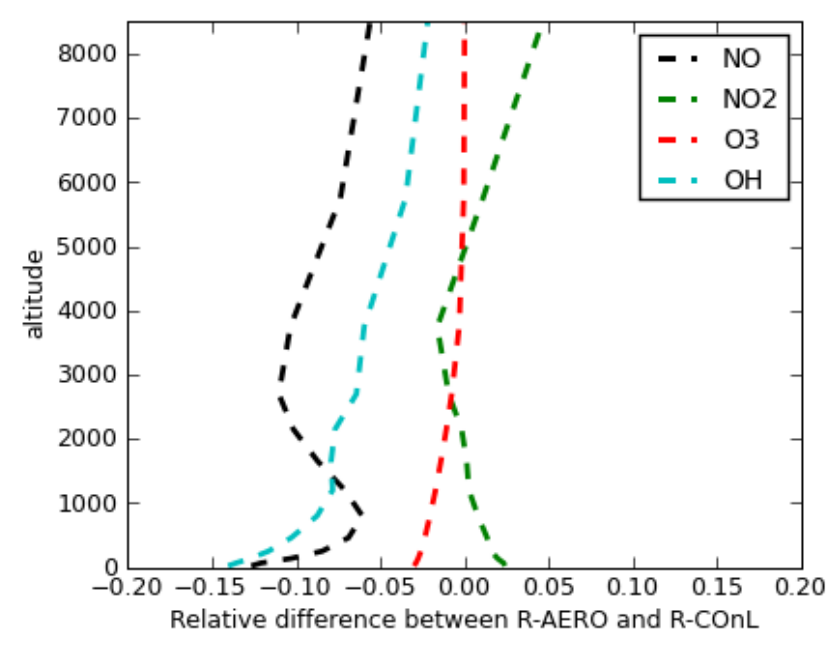

(a) July

Fig. 6. Relative differences between $\mathrm{O}_{3}, \mathrm{NO}, \mathrm{NO}_{2}$ and $\mathrm{OH}$ concentrations simulated with and without aerosol impact on photolysis rates. Values are averaged over Europe for July 2001.

noticeable differences over regions with strong $\mathrm{NO}_{\mathrm{x}}$ emissions, i.e. urban regions where changes are small (see Fig. 8). In these regions, $\mathrm{NO}_{\mathrm{x}}$ concentrations are dominated by emissions, the relative impact of photolysis being less important. However, it should be noticed that, in contrast to the relative local differences, the absolute local differences in NO concentrations are larger over urban regions. As detailed in the previous paragraph, $\mathrm{NO}_{2}$ concentrations increase over most of the domain. Concerning $\mathrm{O}_{3}, \mathrm{O}_{3}$ relative differences are important where one of the 2 terms: chemical $\mathrm{O}_{3}$ production or destruction dominates. For example $\mathrm{O}_{3}$ relative differences are larger around cities or in industrial valleys but also around ship emissions, with reductions up to $8 \%$ (see Fig. 8). In particular, $\mathrm{O}_{3}$ peaks are reduced. Because $\mathrm{O}_{3}$ has a relatively long life time and thus an elevated background, relative 


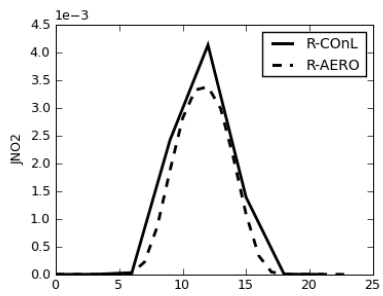

(a) $\mathrm{JNO}_{2}$ - ground

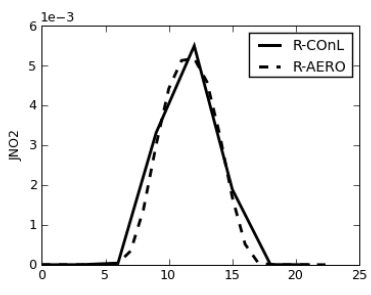

(c) $\mathrm{JNO}_{2}-3 \mathrm{~km}$

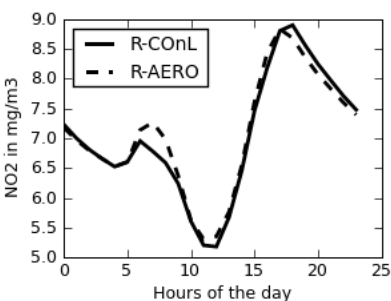

(b) $\mathrm{NO}_{2}$ - ground

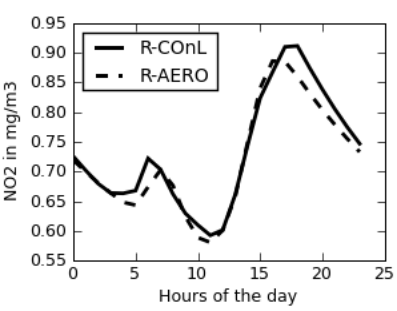

(d) $\mathrm{NO}_{2}-3 \mathrm{~km}$
Fig. 7. Monthly mean daily variations of $\mathrm{JNO}_{2}$ and $\mathrm{NO}_{2}$ concentrations at the ground and at $3 \mathrm{~km}$, for the simulations R-AERO and R-COnL.

differences in rural regions (far from precursors emissions) are small compared to more reactive species such as $\mathrm{OH}$ or NO, which have almost zero background concentrations. All these differences are enhanced in south Europe below dust plumes with mean relative differences in $\mathrm{OH}$ and $\mathrm{NO}$ around $-30 \%$ and $\mathrm{O}_{3}$ and $\mathrm{NO}_{2}$ differences between -8 and $+15 \%$.

The ground map of relative differences in $\mathrm{HNO}_{3}$ concentrations is also shown in Fig. 9. $\mathrm{HNO}_{3}$ is formed by the reaction of $\mathrm{NO}_{2}$ with $\mathrm{OH}$. It can also be formed through the heterogeneous reaction of $\mathrm{N}_{2} \mathrm{O}_{5}$ (at night). Globally, $\mathrm{HNO}_{3}$ concentrations decrease because of the decrease in $\mathrm{OH}$ concentrations that leads to a decrease in $\mathrm{HNO}_{3}$ production during the day. $\mathrm{NO}_{2}$ concentrations increase, increasing $\mathrm{HNO}_{3}$ production, but to a lesser extent. There are two small areas over the Atlantic where $\mathrm{HNO}_{3}$ concentrations increase. They are characterised by low $\mathrm{NO}_{2}$ concentrations and the presence of clouds in the free troposphere. Below clouds, $\mathrm{JO}^{1} \mathrm{D}$ is less reduced than $\mathrm{JNO}_{2}$, each photolysis rate coefficient being sensitive to different wavelengths which are scattered differently inside clouds and aerosol layers. This leads to a lower reduction of $\mathrm{OH}$ concentrations. In contrast, as $\mathrm{NO}_{2}$ concentrations are not dominated by emissions, a decrease in $\mathrm{JNO}_{2}$ leads to a higher relative increase in $\mathrm{NO}_{2}$ concentrations. In this case increase in $\mathrm{HNO}_{3}$ production from $\mathrm{NO}_{2}$ is higher than the decrease in $\mathrm{HNO}_{3}$ production.

As explained in the previous section, the reduction of the oxidising capacity of the atmosphere is specially strong at the ground. This reduction impacts, in particular, the VOC lifetimes, as reactions with $\mathrm{OH}$ are their main sources of chemical production or destruction. For example the ground concentrations of the model species $\mathrm{HC}_{8}$ (aggregation of VOCs

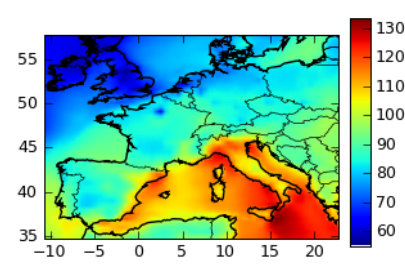

(a) $\mathrm{O}_{3}$

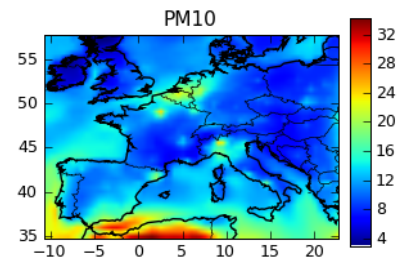

(c) $\mathrm{PM}_{10}$

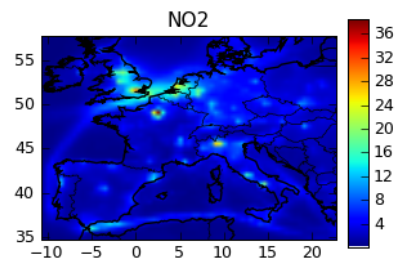

(b) $\mathrm{NO}_{2}$

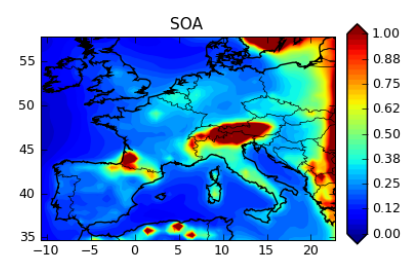

(d) SOA

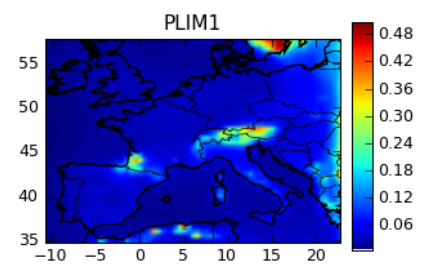

(e) LIM

Fig. 8. Monthly mean concentrations of $\mathrm{O}_{3}, \mathrm{NO}_{2}, \mathrm{PM}_{10}$, $\mathrm{SOA}$ and limonene at the ground for July 2001.

of 8 carbons) and isoprene are increased by respectively 6 and $11 \%$ in July and 2 and $9 \%$ in November. The variations of isoprene are especially high because only $\mathrm{OH}$ concentrations influence the destruction of isoprene (in opposite to $\mathrm{HC}_{8}$, isoprene is not formed through the oxidation of $\mathrm{VOC}$ by $\mathrm{OH}$ but directly emitted).

Not only gas, but also aerosol concentrations are impacted by the aerosol alteration of photolysis rates. Maps of monthly mean relative differences of $\mathrm{PM}_{10}$, nitrate $\left(\mathrm{PNO}_{3}\right)$, sulphate $\left(\mathrm{PSO}_{4}\right)$, ammonium $\left(\mathrm{PNH}_{4}\right)$, and Secondary Organic Aerosols (PSOA) are shown in Fig. 10. The $\mathrm{PSO}_{4}$ concentrations mainly decrease over Europe due to the decrease in $\mathrm{OH}$ concentrations $\left(\mathrm{PSO}_{4}\right.$ is produced by the condensation of $\mathrm{H}_{2} \mathrm{SO}_{4}$, a product of the oxidation of $\mathrm{SO}_{2}$ by $\mathrm{OH}$, and other oxidants such as $\mathrm{H}_{2} \mathrm{O}_{2}$ or $\mathrm{O}_{3}$ ). Depending on the regions, $\mathrm{PNO}_{3}$ concentrations can either increase or decrease when including the aerosol impact on solar radiation. $\mathrm{PNO}_{3}$ is mostly formed by the condensation of $\mathrm{HNO}_{3}$. Therefore, $\mathrm{PNO}_{3}$ relative differences follow that of $\mathrm{HNO}_{3}$ except when $\mathrm{PSO}_{4}$ concentrations are high (over the Mediterranean sea and over north Africa for example). Over these regions, the absolute $\mathrm{PSO}_{4}$ concentrations strongly decrease because of a decrease in $\mathrm{OH}$ and $\mathrm{HNO}_{3}$ tends to condense and replaces $\mathrm{PSO}_{4}$ to neutralize $\mathrm{PNH}_{4}$. $\mathrm{PNH}_{4}$ is formed by the condensation of $\mathrm{NH}_{3}$ onto particles depending on the concentrations 


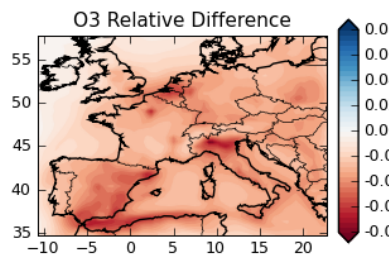

(a) $\mathrm{O}_{3}$

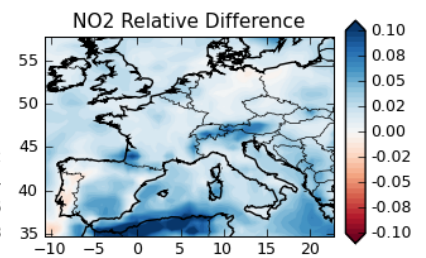

(b) $\mathrm{NO}_{2}$

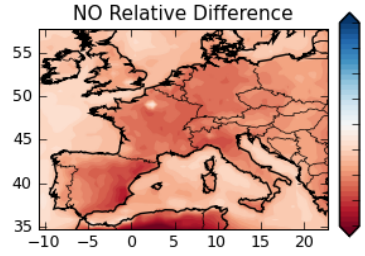

(c) $\mathrm{NO}$

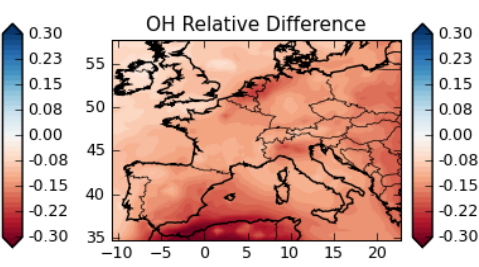

(d) $\mathrm{OH}$

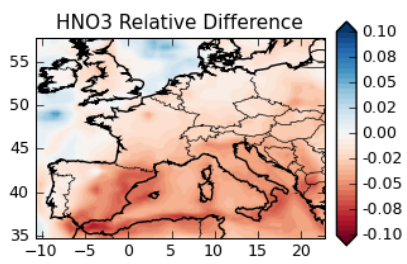

(e) $\mathrm{HNO}_{3}$

Fig. 9. Monthly mean relative differences of $\mathrm{NO}_{2}, \mathrm{NO}, \mathrm{O}_{3}, \mathrm{OH}$ and $\mathrm{HNO}_{3}$ concentrations at the ground between the simulations R-AERO and R-COnL for July 2001.

of $\mathrm{NH}_{3}, \mathrm{HNO}_{3}, \mathrm{PNO}_{3}$ and $\mathrm{PSO}_{4}$. Therefore changes in $\mathrm{PNH}_{4}$ concentrations follow those of $\mathrm{PNO}_{3}$ and $\mathrm{PSO}_{4}$.

SOA concentrations mainly decrease. They are formed by the condensation of semi-volatile organic species (SVOC), which concentrations decrease mainly due to the decrease in $\mathrm{OH}$ concentrations, as they are produced through the oxidation of gas precursors (mainly by $\mathrm{OH}$ ). When looking at SOA concentrations (see Fig. 8), it si clear that two different behaviours are simulated for anthropogenic and biogenic species (PAPI, PLIM). For biogenics, which are abundant over the Alps, around Biarritz and North Africa, relative differences are small, less than -1 or $-2 \%$, although differences around $-10 \%$ are simulated for other anthropogenic SOA. The limiting factor to form SVOC is not the concentrations of $\mathrm{OH}$, but the concentrations of gaseous precursors because of their high $\mathrm{OH}$ reactivity. It should be notice that SOA are probably under-estimated with the SOA model SORGAM (Kim et al., 2011) and the absolute impact on SOA concentrations are expected to be higher.

Overall, although high differences are observed locally for $\mathrm{PNO}_{3}$ and $\mathrm{PSO}_{4}$ (up to $-20 \%$ for $\mathrm{PNO}_{3}$ ) they often compensate each other and the impact on $\mathrm{PM}_{10}$ is low $(-0.2 \%)$, with a maximum of $-8 \%$ over the Po Valley.

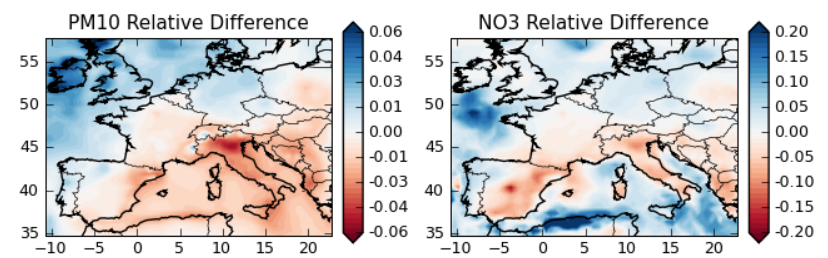

(a) $\mathrm{PM}_{10}$

(b) $\mathrm{PNO}_{3}$

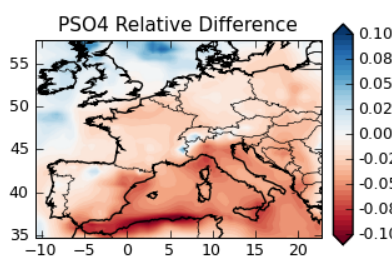

(c) $\mathrm{SO} 4$

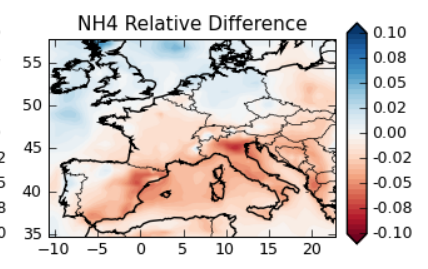

(d) $\mathrm{NH}_{4}$

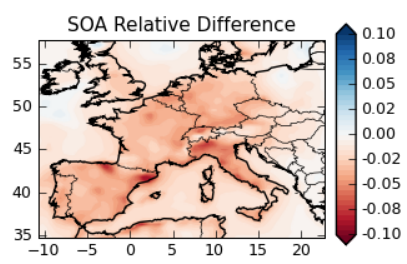

(e) SOA

Fig. 10. Monthly mean relative differences of $\mathrm{PM}_{10}, \mathrm{PNO}_{3}, \mathrm{PSO}_{4}$, $\mathrm{PNH}_{4}$ and PSOA concentrations at the ground between the simulations R-AERO and R-COnL for July 2001.

\subsubsection{Comparisons to previous studies}

In this section, we compare our results with results from literature and try to understand differences.

Several global model were used to asses the impact of aerosols on photolysis rates and on photochemistry (Liao et al., 2003; Martin et al., 2003; Tie et al., 2005) at global scales (with a resolution of $4^{\circ} \times 5^{\circ}$ ). One study has been performed at a regional scale over Asia with a $80 \mathrm{~km} \times 80 \mathrm{~km}$ resolution (Tang et al., 2003). All these studies simulated a mean decrease of photolysis rates due to the impact of aerosols, with the largest decrease at the ground. However, photolysis rate reductions are different between studies. Liao et al. (2003) simulated a small impact of aerosols on photolysis rates whereas a large impact was simulated by the others. The largest decreases were simulated over regions influenced by dust or biomass burning. Over Saharian regions, 30 and $40 \%$ decreases are simulated respectively by Martin et al., 2003 and Tie et al., 2005). Over biomass burning regions, a decrease reaching 50\% was simulated by Martin et al. (2003) and up to $60 \%$ by the regional study of Tang et al. (2003). Over Europe, both Martin et al. (2003) and Tie et al. (2005) simulated the largest impact over the south because of the dust influence (from -10 to $-25 \%$ ) but a high decrease was also simulated in Northern Europe mainly due 
to black carbon emissions. The same range of decrease in photolysis rates are simulated in this paper, with a slightly higher decrease in south Europe (up to -30\%). However the strong reduction in North Europe is not simulated in our study because black carbon emissions are lower.

Differences between the studies may come from (1) the simulated aerosol concentrations, compositions and size distributions (which mainly depend on the aerosol emissions, the aerosol boundary conditions and the aerosol model), (2) the refractive indexes used for individual species (which mainly depend on chemical composition), (3) the way optical properties are computed (internal mixing, external mixing, core shell), (4) the photolysis scheme used and particularly the cross section and quantum yields used. Jeong and Sokolik (2007) showed that for the same mass concentrations of dust aerosols, photolysis rates are highly sensitive to size distribution and mineralogical composition (percentage of iron). This latter changes the refractive index of dust. Differences due to mineralogical composition can be as high as $20 \%$, leading to reductions of photolysis rates below dust clouds from $-20 \%$ to $-45 \%$. In Tie et al. (2005); Martin et al. (2003) and in our study, different individual refractive indexes are used which may by themselves explain the differences simulated under dust conditions, altought differences in size distributions or dust loading also probably play a role on the differences. Jeong and Sokolik (2007) also showed that the way optical properties are computed (internal mixing, external mixing, core shell) do not play a strong role unless black carbon fraction is very high. This was also observed by Tombette et al. (2008). We show that if the same updated cross-sections and quantum yields are used in two photolysis scheme, differences in photolysis rates are small. We therefore expect that the differences come from the aerosol distributions itself, i.e. aerosol emission, boundary conditions and aerosol model followed by the refractive index used for each individual species.

In term of impact on gas concentrations, $\mathrm{O}_{3}$ and $\mathrm{OH}$ comportments are usually similar in all studies, with a linear dependence of $\mathrm{OH}$ with $\mathrm{JO}^{1} \mathrm{D}$ and a maximum impact on $\mathrm{O}_{3}$ where $\mathrm{O}_{3}$ production strongly dominates $\mathrm{O}_{3}$ destruction (biomass burning, city plumes). None of these previous studies analysed the impact on the VOC or aerosols and none of them estimated the impact on simulated air quality standards (see Sect. 3.5.2).

\subsection{Comparison of the impact of photolysis rate modelling to model uncertainties}

An important question is how important are changes induced by including aerosols in photolysis rates calculation compared to changes induces by modifying other parameters or model input data. In order to answer that question, we compared our model results to a sensitivity study conducted by Roustan et al. (2010) with the same model than the one used in our study and for the two months studied here. Roustan et al. (2010) compared a reference simulation to a simulation where one parameter (or data input) is changed. To quantify the influence of the parametrisation, they compared pollutant concentrations at the ground from the reference simulation and from the other simulation in terms of NME, RMSE and NMB (here statistics are relevant to differences between models, no measurement is used). Then they rank the different simulations depending on their statistics. Among the different parametrisations tested, once can cite the boundary layer turbulence diffusion (often first ranked), the number of vertical layers (important for all species), the boundary conditions (important for long-live species), or options related to gas/particle transfer (heterogeneous reaction, gas/particle mass transfer, important for $\mathrm{NO}_{2}$ and aerosols). Here, the same statistics are computed between R-ATT (taken as the reference simulation) and $\mathrm{R}-\mathrm{COnL}$, as well as between $\mathrm{R}-$ COnL (taken as the reference simulation) and R-AERO. These statistics (NME and NMB) are compared to results from Roustan et al. (2010) in Table 6) We have added the impact on $\mathrm{OH}$ concentrations which was calculated but not included in the paper of Roustan et al. (2010). Changing the cloud parametrisation in photolysis rates calculation has a low impact on pollutant concentrations at the ground compared to other parametrisations. The highest impact is observed for $\mathrm{OH}$ concentrations for which $\mathrm{R}-\mathrm{COnL}$ is ranked 5th. Including aerosols in photolysis rate calculation has the highest impact on ground $\mathrm{OH}$ concentrations compared to the other parametrisations tested (first rank for NMB in both winter and summer, first rank for NME in winter and second in summer). This is important for boundary layer life-time of several species such as VOC and SOA. R-AERO also has the second highest impact on NO concentrations after the parametrisation of vertical diffusion. Impact on $\mathrm{PM}_{10}$ and $\mathrm{NO}_{2}$ compared to other parametrisations is low. The impact on $\mathrm{O}_{3}$ is high when simulations are compared in term of bias: in summer it has the highest impact on $\mathrm{O}_{3}$ bias, just after the vertical diffusion parametrisation. This high impact on $\mathrm{O}_{3}$ bias is due to systematic reduction of strong net $\mathrm{O}_{3}$ production.

\subsection{Impact on air quality simulation}

\subsubsection{Comparisons of ground model concentrations to observations}

To estimate the modelling of particles which impact photolysis rates in R-AERO, the simulated AOD is compared to OD measured from the AERONET network in Table 2. Simulated AOD are similar to those observed. As discussed in Sect. 2.2, dust boundary conditions from the GOCART simulation had to be divided by 4 to obtain realistic AOD. Model concentrations of $\mathrm{O}_{3}, \mathrm{NO}_{2}$ and $\mathrm{PM}_{10}$ at the ground are compared to the European ground base stations EMEP $\left(\mathrm{O}_{3}, \mathrm{NO}_{2}\right.$ and $\left.\mathrm{PM}_{10}\right)$. Stations from the EMEP network are representative of "background" concentrations, i.e. suitable 
Table 6. Comparative table between the work of Roustan et al. (2010) and this paper. Statistics of comparisons are given for July and November 2001 in terms of NME and NMB. Results of Roustan et al., for 29 different simulations are given as mean /max. Rank of statistics results between R-AERO vs. R-COnL and R-COnL vs. R-ATT are given compared to the results of the results of Roustan et al.

\begin{tabular}{|c|c|c|c|c|c|c|c|c|c|c|c|}
\hline \multirow[b]{2}{*}{$=$} & & \multicolumn{2}{|c|}{ Roustan et al. } & \multicolumn{2}{|c|}{ R-COnL vs. R-ATT } & \multicolumn{2}{|c|}{ rank } & \multicolumn{2}{|c|}{ R-AERO vs. R-COnL } & \multicolumn{2}{|c|}{ rank } \\
\hline & & NME & NMB & NME & NMB & NME & NMB & NME & NMB & NME & NMB \\
\hline \multirow{5}{*}{ Summer } & $\mathrm{O}_{3}$ & $1.9 / 13.5$ & $-0.08 /-8.6$ & 1.7 & 0.5 & 9th & 17th & 3.6 & -3.5 & 5th & 2nd \\
\hline & $\mathrm{NO}_{2}$ & $4.1 / 49.2$ & $0.66 / 48$ & 0.2 & -1.1 & 21th & 11th & 4.7 & 2.5 & 6th & 6th \\
\hline & $\mathrm{PM}_{10}$ & $5.1 / 29.2$ & $0.84 / 19.7$ & 0.6 & 0.9 & 26th & 24th & 2.2 & -0.14 & 17th & 27 th \\
\hline & $\mathrm{OH}$ & $2.41 / 19.8$ & $-0.7 /-9.3$ & 5.6 & 1.9 & 5th & 5 th & 15.3 & -14 & 2nd & 1 th \\
\hline & NO & $6.9 / 98$ & $2.7 / 96$ & 6.5 & -2 & 7th & 8th & 14.8 & -12.7 & 2nd & 2 nd \\
\hline \multirow{5}{*}{ Winter } & $\mathrm{O}_{3}$ & $1.8 / 15.8$ & $-0.1 /-14.9$ & 0.7 & -0.08 & 11th & 19th & 2.4 & -2.7 & 7th & 4th \\
\hline & $\mathrm{NO}_{2}$ & $5.4 / 38.5$ & $1.7 / 37$ & 0.3 & 0.3 & 22th & 13th & 3.5 & 0.7 & 9th & 9 th \\
\hline & $\mathrm{PM}_{10}$ & $5.8 / 20.6$ & $0.3 / 15.3$ & 0.5 & 0.7 & 26th & 22th & 2.6 & 2.27 & 18th & 14 th \\
\hline & $\mathrm{OH}$ & $2.1 / 18.3$ & $-1.6 /-11.2$ & 0.14 & 1.9 & 5 th & 6th & 18.6 & -15.9 & 1th & 1th \\
\hline & NO & $5.8 / 73$ & $2.4 / 71$ & 7.7 & -1.9 & 8th & 8th & 16 & -13.4 & 2nd & 2nd \\
\hline
\end{tabular}

for regional model comparison. For $\mathrm{O}_{3}$, results are also compared to the Airbase network, with stations located closer to pollution centres.

For EMEP, comparisons are shown for the 3 simulations: R-ATT (our reference simulation), R-COnL and R-AERO for the months of July and November (Table 4). Statistics are not strongly influenced by the parametrisation used for clouds (R-COnL versus R-ATT). Scores are slightly better with R-COnL with maximum differences in winter. As those differences are small, this comparison is not shown for Airbase stations. Statistics are slightly more influenced by RAERO (aerosol impact on photolysis rates) than R-COnL. The largest differences are observed for hourly $\mathrm{O}_{3}$ and $\mathrm{O}_{3}$ peaks, with a decrease in RMSE up to $2 \mu \mathrm{g} \mathrm{m}^{-3}$ at Airbase stations. Comparisons with $\mathrm{OH}$ measurements would exhibit strongest differences but such measurements are not available on a regular basis over Europe. For $\mathrm{O}_{3}$, both $\mathrm{O}_{3}$ peaks and hourly $\mathrm{O}_{3}$ are better reproduced with R-AERO at EMEP and Airbase stations. The bias is systematically reduced by several per cent for both months and both networks. The errors (RMSE and NME) and correlation coefficients respectively decrease and increase with R-AERO excepted in July for $\mathrm{O}_{3}$ peaks at EMEP stations. In that case (July at EMEP stations), R-AERO leads to an under-estimation of $\mathrm{O}_{3}$ peaks when in all other cases, the reference model over-estimates hourly and peaks $\mathrm{O}_{3}$, explaining the better reproduction of $\mathrm{O}_{3}$ measurements with R-AERO. Statistics differences between R-AERO and R-COnL are low for $\mathrm{NO}_{2}$ and $\mathrm{PM}_{10}$.

\subsubsection{Impact on exeedances of air quality standards}

It was previously shown that taking into account aerosols when computing photolysis rates at the ground leads to a slight decrease in mean $\mathrm{O}_{3}$ concentrations but also to a decrease in $\mathrm{O}_{3}$ peaks. The decrease in $\mathrm{O}_{3}$ peaks is larger than the decrease in mean $\mathrm{O}_{3}$ concentrations because peaks corre- spond to cases where $\mathrm{O}_{3}$ production is much larger than $\mathrm{O}_{3}$ destruction. Exceedance of the $\mathrm{O}_{3}$ standards for $\mathrm{O}_{3}$ peaks is the criterion used by authorities (e.g. in France) to inform the public about high pollution episodes. If exceedances of the $\mathrm{O}_{3}$ standards are to be obtained from numerical simulations rather than observations (in the framework of forecasting for example), the impact of aerosols on photochemistry may be important. We calculate these standards over each model grid for R-COnL and R-AERO. For $\mathrm{O}_{3}$ information standard (hourly concentrations $>180 \mu \mathrm{g} \mathrm{m}^{-3}$ ), about half of the $\mathrm{O}_{3}$ exceedances are not simulated when taking solar radiation attenuation into account. Exceedances of the alert standard (hourly concentrations $>240 \mu \mathrm{g} \mathrm{m}^{-3}$ ) are also divided by 2 (not shown). Those differences are particularly important because emissions of $\mathrm{O}_{3}$ precursors and aerosols emissions are usually collocated. Therefore the AOD is particularly strong where $\mathrm{O}_{3}$ production is the largest leading to strong $\mathrm{O}_{3}$ peak reductions.

In order to evaluate if this simulated decrease in numbers of exceedance of the $\mathrm{O}_{3}$ threshold correspond to a real feature, we compared it to the measurements. The number of $\mathrm{O}_{3}$ exceedances measured and simulated with and without including aerosols in photolysis calculation is compared at the Airbase stations in Table 7 (as EMEP are "background" stations, exceedances of pollutant threshold are rare). This number is overestimated with R-COnL with a bias of $23 \%$. R-AERO simulation reduces significantly this bias to $2 \%$. The RMSE is also reduced. However, the NME is slightly larger with R-AERO than R-COnL and the correlation coefficient is slightly lower. The significance of the bias reduction (larger than any other changes on computed statistics in Table 4 and Table 7) and the RMSE reduction suggests that R-AERO better reproduces $\mathrm{O}_{3}$ peaks and exceedance of $\mathrm{O}_{3}$ information threshold. 
Table 7. Statistics obtained when comparing exceedance of $\mathrm{O}_{3}$ information threshold measured and simulated at AIRBASE stations with R-COnL and R-AERO in July. Mean values and RMSE are reported in $\mu \mathrm{g} \mathrm{m}^{-3}$, and RMSE, NMB and NME in \%. Comparison is done at 734 stations.

\begin{tabular}{lrrrrr}
\hline & mean & r & RMSE & NMB & NME \\
\hline Meas & 24.7 & & & & \\
R-COnL & 32.2 & $76.4 \%$ & 36.4 & $23 \%$ & $53 \%$ \\
R-AERO & 25.4 & $73 \%$ & 34.5 & $2 \%$ & $59 \%$ \\
\hline
\end{tabular}

This strong reduction of the bias is coherent with results from Sect. 3.4, where it was shown that over 31 different model parametrisations, R-AERO has the largest impact on $\mathrm{O}_{3}$ bias. It is therefore probable that $\mathrm{R}-\mathrm{AERO}$ will lead to the highest systematic reduction of $\mathrm{O}_{3}$ information threshold exceedances.

\section{Conclusions}

The impact of photolysis rate calculation on simulated European air composition and air quality is studied. To do so, the photolysis scheme Fast-JX is used (1) to update the tabulated clear-sky photolysis rate coefficients used in the CTM Polair3D (2) to more realistically simulate cloud impact on photolysis rates by taking into account clouds directly in the computation of photolysis rates in Fast-JX rather than using the "attenuation coefficient" method (3) to take into account aerosol impact on photolysis rates by coupling FAST-JX and the CTM Polair3D. Two months are chosen to perform the simulations: July and November 2001.

The clear-sky tabulated rates calculated with FAST-JX exhibit large differences with those calculated with the photolysis scheme J-PROC, which were previously used. Most photolysis rates show a large increase, mainly due to differences in cross-section and quantum yields data.

Taking clouds into account directly when computing photolysis rates leads to differences in photolysis rates mainly inside clouds. In general, the highest the cloud optical depth is, the largest the differences are. Outside clouds, and especially at the ground, differences are small. In terms of gas tropospheric burden, the highest impact is simulated for $\mathrm{OH}$ burden, which increases by 4 to $5 \%$. In term of air quality (ground concentrations) this more realistic parametrisation of clouds has no strong impact on ground simulated species.

Taking into account the impact of aerosols on photolysis rates leads to larger differences both in photolysis rates and concentrations. The higher impact on photolysis rates is observed at the ground and it decreases with altitude. At the ground, monthly mean $\mathrm{NO}_{2}$ and $\mathrm{O}_{3}$ photolysis rate coefficients are reduced by $12-14 \%$ in summer. Dust is the aerosol species which impact the most photolysis rates. Its impact is particularly High in south Europe as it is trans- ported from North Africa. High impact is also observed over anthropogenic emission regions (Paris, The Po and the Ruhr Valley) where mainly $\mathrm{PNO}_{3}$ and $\mathrm{PSO}_{4}$ reduced the incoming radiation. Differences in photolysis rates lead to changes in species concentrations, with the highest impact simulated on $\mathrm{OH}$ and NO. Monthly mean ground concentrations of both species are reduced by around 10 to $14 \%$. More generally, the tropospheric burden of $\mathrm{OH}$ and $\mathrm{NO}$ decreases by around $10 \%$. The decrease in $\mathrm{OH}$, strong oxidant species, leads to an increase in the life-time of several species and in particular several VOCs such as isoprene (10\% increase). Tropospheric $\mathrm{NO}_{2}$ concentrations are not highly impacted. $\mathrm{O}_{3}$ concentrations mostly decrease at the ground $(-3 \%)$. But one of the highest impact of solar radiation modification by aerosols is to systematically reduce high $\mathrm{O}_{3}$ peak values by reducing $\mathrm{NO}_{2}$ photolysis rates. Not only gas concentrations are impacted by the solar radiation alteration by aerosols but also secondary aerosol concentrations. However, changes in aerosol species concentrations often compensate each other, resulting in an increase in $\mathrm{PM}_{10}$ and $\mathrm{PM}_{2.5}$ ground-burden lower than $2 \%$. However, local $\mathrm{PM}_{10}$ and $\mathrm{PM}_{2.5}$ relative differences can decrease by as much as $8 \%$ (in the Po valley for example).

The changes in gas concentrations at the ground induced by the modification of photolysis rates (by aerosols and clouds) are compared to changes induced by 29 different model parametrisations in Roustan et al. (2010). Among the 31 model parametrisations, including aerosols in photolysis rates calculation has the highest impact on $\mathrm{OH}$ concentrations and on $\mathrm{O}_{3}$ bias in July.

In terms of air quality monitoring, ground concentrations are compared with concentrations from the EMEP $\left(\mathrm{O}_{3}, \mathrm{NO}_{2}\right.$ and $\left.\mathrm{PM}_{10}\right)$ and AIRBASE $\left(\mathrm{O}_{3}\right.$ only) networks. Changing the cloud parametrisation does not strongly affect the simulation performances. Changes are larger when including aerosols in photolysis rate calculation but remain relatively small. Scores (for hourly and peak $\mathrm{O}_{3}, \mathrm{NO}_{2}$ and $\mathrm{PM}_{10}$ ) are generally improved. Exceedances of the European information $\mathrm{O}_{3}$ threshold is also compared to measurements at AIRBASE stations. This threshold is best reproduced with the simulation including aerosol in photolysis rates calculation with a strong reduction of the model over-estimation due to a systematic reduction of high $\mathrm{O}_{3}$ production. This results in large differences in exceedances of the European $\mathrm{O}_{3}$ standard as calculated by the model: the numbers of exceedances of the information and the alert standard are divided by 2 when including the impact of aerosols on photolysis rates.

Acknowledgements. We thank Oliver Wild and Michael J. Prather for use of the Fast-JX model. We are also grateful to Michael Mishchenko for providing the Mie code used in this paper and to Marilyne Tombette for useful informations on optical properties calculation.

Edited by: P. Monks 


\section{References}

Barnard, J. C., Chapman, E. G., Fast, J. D., Schmelzer, J. R., Slusser, J. R., and Shetter, R. E.: An evaluation of the FAST-J photolysis algorithm for predicting nitrogen dioxide photolysis rates under clear and cloudy sky conditions, Atmos. Environ., 38, 3393-3403, 2004.

Briegleb, B. P.: Delta-Eddington Approximation for Solar Radiation in the NCAR Community Climate Model, J. Geophys. Res., 97, 7603-7612, 1992.

Chang, J., Brost, R., Isaken, I., Madronich, S., Middleton, P., Stockwell, W., and Walcek, C.: A three-dimensional Eulerian acid deposition model: physical concepts and formulation, J. Geophys. Res., 102, 14681-14700, 1987.

Chin, M., Rood, R., Lin, S.-J., Muller, J., and Thomspon, A.: Atmospheric sulfur cycle in the global model GOCART: model description and global properties, J. Geophys. Res., 105, 2467124687, 2000.

Debry, E., Fahey, K., Sartelet, K., Sportisse, B., and Tombette, M.: Technical note: a new SIze REsolved Aerosol Model (SIREAM), ACP, 7, 1537-1547, 2007.

Demerjian, K. L., Schere, K., and Peterson, J.: Theoretical estimates of actinic (spherically integrated) flux and photolytic rate constants of atmospheric species in the lower troposphere, Adv. Environ. Sci. Technol., 10, 369-459, 1980.

DeMore, W.B., Sander, S., Golden, D., Hampson, R., Kurylo, M., Howard, C., Ravishankara, A., Kolb, C., and Molina, M.: Chemical Kinetics and Photochemical Data for Use in Stratospheric Modeling: Evaluation Number 11, Tech. rep., 1994.

Dickerson, R. R., Kondragunta, S., Stenchikov, G., Civerolo, K. L., Doddridge, B. G., and Holben, B. N.: The Impact of Aerosols on Solar Ultraviolet Radiation and Photochemical Smog, Science, 278, 827-830, 1997.

Elterman, L.: UV, Visible, and IR Attenuation for Altitudes to 50 km, Tech. rep., AFCRL-68-0153. Bedford, MA: Air Force Cambridge Res. Lab., 1968.

Fahey, K. and Pandis, S.: Size-resolved aqueous-phase chemistry in a three-dimensional chemical transport model, J. Geophys. Res., 108, 4690, doi:10.1029/2003JD003564, 2003.

Feng, Y., Penner, J. E., Sillman, S., and Liu, X.: Effects of cloud overlap in photochemical models, J. Geophys. Res., 109, D04310, doi:10.1029/2003JD004040, 2004.

Gery, M., Whitten, G., Killus, J., and Dodge, M.: A photochemical mechanism for urban and regional scale computer modeling, J. Geophys. Res., 94, 12925-12956, 1989.

He, S. and Carmichael, G. R.: Sensitivity of photolysis rates and ozone production in the troposphere to aerosol properties, J. Geophys. Res., 104, 26307-26324, 1999.

Hess, M., Koepke, P., and Schult, I.: Optical properties of aerosols and clouds: The software package OPAC, Bulletin of the American Meteorological Society, 79, 831-845, 1998.

Horowitz, L., Walters, S., Mauzerall, D., Emmons, L., Rasch, P., Granier, C., Tie, X., Lamarque, J.-F., Schultz, M., Tyndall, G., Orlando, J., and Brasseur, G.: A global simulation of tropospheric ozone and related tracers: Description and evaluation of MOZART, version 2, J. Geophys. Res., 108, 4784, doi:10.1029/2002JD002853, 2003.

Jeong, G.-R. and Sokolik, I. N.: Effect of mineral dust aerosols on the photolysis rates in the clean and polluted marine environments, J. Geophys. Res., 112, 387-422, 2007.
Joseph, J., Wiscombe, W., and Weinman, J.: The delta-Eddington approximation for radiative flux transfer, J. Atmos. Sci., 33, 2452-2459, 1976.

Kim, J., Couvidat, F., Sartelet, K., and Seigneur, C.: Comparison of different gas-phase mechanisms and aerosol modules for simulating particulate matter formation, J. Air Waste Manage. Assoc., in press, 2011.

Labow, G. J., McPeters, R. D., and Bhartia, P. K.: A comparison of TOMS and SBUV version 8 total column ozone data with data from ground stations, Proceedings of the XX Quadrennial Ozone Sympo- sium, edited by: C. S. Zerefos, Int. Ozone Comm., Athen, 123-124, 2004.

Lefer, B. L., Shetter, R. E., Hall, S. R., Crawford, J. H., and Olson, J. R.: Impact of clouds and aerosols on photolysis frequencies and photochemistry during TRACE-P: 1 . Analysis using radiative transfer and photochemical box models, J. Geophys. Res., 108, 8821, doi:10.1029/2002JD003171, 2003.

Liao, H., Adams, P. J., Chung, S. H., Seinfeld, J. H., Mickley, L. J., and Jacob, D. J.: Interactions between tropospheric chemistry and aerosols in a unified general circulation model, J. Geophys. Res., 108, 4001, doi:10.1029/2001JD001260, 2003.

Liu, H., Crawford, J. H., Pierce, R. B., Norris, P., Platnick, S. E., Chen, G., Logan, J. A., Yantosca, R. M., Evans, M. J., Kittaka, C., Feng, Y., and Tie, X.: Radiative effect of clouds on tropospheric chemistry in a global threedimensional chemical transport model, J. Geophys. Res., 111, 20303, doi:10.1029/2005JD006403, 2006.

Mallet, V.: Estimation de l'incertitude et prevision d'ensemble avec un modle de chimie-transport, Tech. rep., These de doctorat de l'ENPC, 2005.

Martin, R. V., Jacob, D. J., Yantosca, R. M., Chin, M., and Ginoux, P.: Global and regional decreases in tropospheric oxidants from photochemical effects of aerosols, J. Geophys. Res., 108, 4097, doi:10.1029/2002JD002622, 2003.

Mishchenko, M. I., Goegdzhayev, I., Cairns, B., Rossow, W. B., and Lacis, A. A.: Aerosol retrievals over the ocean by use of channels 1 and 2 AVHRR data: sensitivity analysis and preliminary results, Appl. Optics, 38, 7325-7341, 1999.

Nenes, A., Pandis, S. N., and Pilinis, C.: Continued development and testing of a new thermodynamic aerosol module for urban and regional air quality models, Atmos. Environ., 33, 15531560, 1999.

Pour-Biazar, A., McNider, R. T., Roselle, S. J., Suggs, R., Jedlovec, G., Byun, D. W., Kim, S., Lin, C. J., Ho, T. C., Haines, S., Dornblaser, B., and Cameron, R.: Correcting photolysis rates on the basis of satellite observed clouds, J. Geophys. Res., 112, D10302, doi:10.1029/2006JD007422, 2007.

Pozzoli, L., Bey, I., Rast, S., Schultz, M. G., Stier, P., and Feichter, J.: Trace gas and aerosol interactions in the fully coupled model of aerosol-chemistry-climate ECHAM5HAMMOZ: 1. Model description and insights from the spring 2001 TRACE-P experiment, J. Geophys. Res., 113, D07308, doi:10.1029/2007JD009007, 2008.

Rockel, B., Raschke, E., and Weyres, B.: A parametrization of broad band radiative transfer properties of water, ice and mixed clouds, Beitr. Phys. Atmosph., 64, 1-12, 1991.

Roselle, S. J., Schere, K. L., and Pleim, J. E.: Chapter 14: PHOTOLYSIS RATES FOR CMAQ, Science Algorithms of the EPA Models-3 Community Multiscale Air Quality (CMAQ) Model- 
ing System, 1999.

Roustan, Y. and Bocquet, M.: Sensitivity analyse for mercury over Europe, J. Geophys. Res., 111, D14304, doi:10.1029/2005JD006616, 2006.

Roustan, Y., Sartelet, K. N., Tombette, M., Debry, E., and Sportisse, B.: Simulation of aerosols and gas-phase species over Europe with the Polyphemus system. Part II: model sensitivity analysis for 2001, Atmos. Environ., 44, 4219-4229, 2010.

Sander, S., Friedl, R. R., Ravishankara, A. R., Golden, D. M., Kolb, C. E., Kurylo, M. J., Molina, M. J., Huie, R. E., Orkin, V. L., Moortgat, G. K., and Finlayson-Pitts, B. J.: Chemical Kinetics and Photochemical Data for Atmospheric Studies, JPL Pub. 0225, Jet Propulsion Lab, Pasadena, CA, 2003, 2002.

Sander, S. P., Golden, D. M., Kurylo, M. J., Moortgat, G. K., Wine, P. H., Ravishankara, A. R., Kolb, C. E., Molina, M. J., FinlaysonPitts, B. J., Huie, R. E., and Orkin, V. L.: Chemical kinetics and photochemical data for use in Atmospheric Studies Evaluation Number 15, Tech. rep., 2006.

Sartelet, K., Debry, E., Fahey, K., Roustan, Y., Tombette, M., and Sportisse, B.: Simulation of aerosols and gas-phase species over Europe with the Polyphemus system: Part I-Model-to-data comparison for 2001, Atmos. Environ., 41, 6116-6131, 2007.

Sartelet, K., Hayani, H., and Sportisse, B.: MICS Asia phase II: Sensitivity to the aerosol module, Atmos. Environ., 42, 35623570., 2008.

Schell, B., Ackermann, I., Hass, H., Binkowski, F., and Ebel, A.: Modeling the formation of secondary organic aerosol within a comprehensive air quality model system, J. Geophys. Res., 106, 28275-28293, 2001.

Stephens, G. L.: Radiation profiles in extended water clouds II: parametrisation schemes, J. Atmos. Sci., 35, 2123-2132, 1978.

Stockwell, W. R., Kirchner, F., and Kuhn, M.: A new mechanism for regional atmospheric chemistry modelling, J. Geophys. Res., 102, 25847-25879, 1997.

Tang, Y., Charmichael, G. R., Woo, J.-H., Thongboonchoo, N., Kurata, G., Uno, I., Streets, D. G., Blake, D. R., Weber, R. J., Talbot, R. W., Kondo, Y., Singh, H. B., and Wang, T.: Influences of biomass burning during the Transport and Chemical Evolution Over the Pacific (TRACE-P) experiment identified by the regional chemical transport model, J. Geophys. Res., 108(D21), 8824, doi:10.1029/2002JD003110, 2003.
Tie, X., Madronich, S., Walters, S., Edwards, D. P., Ginoux, P., Mahowald, N., Zhang, R., Lou, C., and Brasseur, G.: Assessment of the global impact of aerosols on tropospheric oxidants, J. Geophys. Res., 110, D03204, doi:10.1029/2004JD005359, 2005.

Tombette, M., Chazette, P., Sportisse, B., and Roustan, Y.: Simulation of aerosol optical properties over Europe with a 3-D sizeresolved aerosol model: comparisons with AERONET data, Atmos. Chem. Phys., 8, 7115-7132, doi:10.5194/acp-8-7115-2008, 2008.

Vautard, R., Bessagnet, B., Chin, M., and Menu, L.: On the contribution of natural Aeolian sources to particulate matter concentrations in Europe: Testing hypotheses with a modelling approach, Atmos. Environ., 39, 3291-3303, 2005.

Voulgarakis, A., Savage, N. H., Wild, O., Carver, G. D., Clemitshaw, K. C., and Pyle, J. A.: Upgrading photolysis in the pTOMCAT CTM: model evaluation and assessment of the role of clouds, Geosci. Model Dev., 2, 59-72, doi:10.5194/gmd-2-592009, 2009.

Wang, P.-H., McCormick, M. P., Chu, W. P., Lenoble, J., Nagatani, R. M., Chanin, M. L., Barnes, R. A., Schmidlin, F., and Rowland, M.: SAGE II Stratospheric Density and Temperature Retrieval Experiment, J. Geophys. Res., 97, 843-863, 1992.

Wild, O. and Akimoto, H.: Intercontinental transport of ozone and its precursors in a three-dimensional global CTM, J. Geophys. Res., 106, 27729-27744, 2001.

Wild, O., Zhu, X., and Prather, M. J.: Fast-J: Accurate Simulation of In- and Below-Cloud Photolysis in Tropopsheric Chemical Models, J. Atmos. Chem., 37, 245-282, 2000. 